\title{
THE ROLE OF INTERMEDIARY CARBOHYDRATE METABOLISM IN REGULATING ORGANIC IODINATIONS IN THE THYROID GLAND *
}

\author{
By GEORGE C. SCHUSSLER and SIDNEY H. INGBAR † with the tech NiCAL assistance \\ oF PATRICIA EVELETH
}

(From the Thorndike Memorial Laboratory, Second and Fourth (Harvard) Medical Services, Boston City Hospital, and the Department of Medicine, Harvard Medical

School, Boston, Mass.)

(Submitted for publication February 16, 1961 ; accepted April 13, 1961)

As pointed out in recent reviews $(1,2)$, the synthesis of hormonally active materials by the thyroid gland proceeds via a sequence of seemingly discrete reactions. These may be categorized as follows: concentration of inorganic iodide from the extracellular fluid, oxidation and organic binding of iodine to yield iodotyrosines, and coupling of iodotyrosines to form the hormonally active iodothyronines. The latter two groups of reactions occur within the matrix of the thyroglobulin molecule, a large molecular protein for whose synthesis and storage the thyroid gland is especially adapted.

It seems clear that ultimately the energy for these synthetic processes, as well as for the maintenance of glandular architecture, must derive from metabolic sources. However, little is known of how the energy released during intermediary metabolism is imparted to those reactions involved in hormonal biosynthesis. Previous studies have indicated that the iodide-concentrating function of the thyroid is dependent on oxidative processes leading to the formation of high energy phosphate bonds $(3,4)$. The present studies were undertaken to determine whether a comparable link to metabolic events could be delineated in the case of the next stage in hormonal synthesis, the oxidation of iodide and formation of monoiodotyrosine. From the results obtained, a metabolic sequence is postulated whereby the oxidation of

* This investigation was supported in part by $\mathrm{Re}$ search Grant no. A-267 from the National Institute of Arthritis and Metabolic Diseases, Bethesda, Md., and in part by the Medical Research and Development Board, Office of the Surgeon General, Department of the Army, under Contract no. DA-49-007-MD-412. Presented in part at the 1959 meeting of the Endocrine Society, June 2, 1959, Atlantic City, N. J.

† Investigator, Howard Hughes Medical Institute. iodide is regulated by glucose metabolism via reactions coupled to pyridine nucleotide-linked dehydrogenations. Evidence is presented which suggests that the effects of thyrotropin (TSH) on organic iodinations in the thyroid may be mediated by an enhancement of glucose metabolism within the gland.

\section{METHODS}

Experiments were performed with slices or homogenates prepared from thyroid glands which had been obtained at the abattoir from freshly killed sheep or lambs and brought to the laboratory packed in ice. Throughout the preparative procedure, the tissues were chilled at 0 to $4^{\circ} \mathrm{C}$.

Preparation of homogenates. Several thyroid glands were employed in the preparation of a single homogenate. Thyroids were stripped of fat and fascia, minced with a Stadie-Riggs blade and homogenized with a PotterElvehjem glass homogenizer in 5 vol of a medium containing phosphate buffer ( $\mathrm{pH} 7.4$ ), $6 \times 10^{-3} \mathrm{M} ; \mathrm{MgSO}_{4}$, $3 \times 10^{-3} \mathrm{M} ; \mathrm{KCl}, 0.14 \mathrm{M}$. Usually, homogenates were rehomogenized with a tight-fitting Teflon homogenizer prior to incubation. No further efforts were made to eliminate intact cells. Since it was the purpose of these experiments to relate organic iodination to carbohydrate metabolism, the medium chosen was identical in terms of inorganic constituents to that described by Wenner, Dunn and Weinhouse as supporting glycolysis in cellfree systems (5). Aliquots of homogenate $(1.7 \mathrm{ml})$ were pipetted into the main compartment of Warburg vessels. In many experiments, the sodium salt of glucose-6-phosphate ${ }^{1}$ was added to a final concentration of $0.015 \mathrm{M}$. After gassing of flasks had been completed and

1 The following abbreviations will be used in text, tables and illustrations: glucose-6-phosphate, G-6-P; triphosphopyridine nucleotide (oxidized), TPN ; triphosphopyridine nucleotide (reduced), TPNH; diphosphopyridine nucleotide (oxidized), DPN ; diphosphopyridine nucleotide (reduced), DPNH; flavin adenine dinucleotide (oxidized), FAD; flavin mononucleotide (oxidized), FMN; glutathione (oxidized), GSSG; glutathione (reduced), GSH; methylene blue (oxidized), MB; norethylmaleimide, NEM. 
temperature equilibration achieved, the final volume of homogenate was brought to $2 \mathrm{ml}$ by tipping into the main compartment $300 \mu \mathrm{l}$ of medium containing $23 \mu \mathrm{c}$ of carrier-free inorganic $\mathrm{I}^{131}, 2$ and the substrates, cofactors, enzymes or inhibitors to be tested. $\mathrm{CO}_{2}$ was absorbed by $300 \mu \mathrm{l}$ of 10 per cent $\mathrm{KOH}$ in another side-arm or in the center well. Incubation was usually carried out for 1 hour in a Warburg apparatus at $38^{\circ} \mathrm{C}$, under an atmosphere of 100 per cent oxygen. A few experiments were performed in Erlenmeyer flasks under oxygen in a metabolic shaker.

In certain experiments, an alternative method was employed. When materials to be tested had limited solubility, these were dissolved together with the radioactive iodide in $1 \mathrm{ml}$ of medium. A more concentrated homogenate was then added to achieve a final homogenate of the usual volume and concentration. A similar procedure was followed in homogenate experiments with $\mathrm{C}^{14}$-labeled glucose ${ }^{3}$ in order that the exact quantity of radioactivity added to each vessel could be determined. In the latter experiments, the final concentration of glucose was 0.3 to $0.5 \mathrm{mg}$, containing $1 \mu \mathrm{c}$ of glucose- $\mathrm{C}^{14}$, per $\mathrm{ml}$.

Prcparation of slices. Thyroid slices, rather than homogenates, were employed in experiments designed to assess the effects of TSH on the metabolism of $\mathrm{C}^{\mathbf{4}}$-labeled

$$
\left.I^{131} \text { organified (per cent }\right)=\frac{\left(I^{131} \text { in precipitate }\right) \times 100}{\left(I^{131} \text { in precipitate }\right)+\left(I^{131} \text { in pooled supernatant }\right)} .
$$

Chromatographic methods were used to characterize the nature of the iodinated products formed by the homogenate. Aliquots of homogenate $(20 \mu 1)$ together with carrier iodide, mono- and diiodotyrosine (MIT and DIT), were applied directly to strips of Whatman no. 1 filter paper. Following chromatography in butanol: dioxane: $2 \mathrm{~N}$ ammonia $(4: 1: 5)$ and in butanol:2 $\mathrm{N}$ acetic acid (1:1) systems, $^{5}$ radioautographs were prepared. Car-

2 Inorganic $\mathrm{I}^{131}$ was obtained from Abbott Laboratories, Oak Ridge, Tenn., and was free, by paper chromatography, of noniodide contaminants described by other workers (6).

${ }^{3} \mathrm{C}^{14}$-labeled glucose was obtained from the New England Nuclear Corp., Boston, Mass. Samples were apparently pure according to radioactive scans of chromatographic strips. Radioautography of samples chromatographed in butanol:acetic acid: water (78:10:12) occasionally revealed a faint band in the zone occupied by labeled lactic acid. Direct counting of these zones revealed that this area contained no more than 0.1 per cent of the total counts on the strip (7). Measurement of this contaminant as $\mathrm{C}^{14} \mathrm{O}_{2}$ could not have accounted for a significant proportion of the acid volatile counts produced by homogenates under the influence of stimulatory cofactors.

4 Thytropar, Armour.

${ }^{5}$ Chromatographic solvents were enriched with propylthiouricil in order to prevent oxidation of compounds during chromatography. glucose. Slices, 50 to $100 \mathrm{mg}$ in weight, were cut with a Stadie-Riggs microtome and were incubated in $2 \mathrm{ml}$ of Krebs-Ringer-phosphate medium (KRP) containing $1 \mu \mathrm{c}$ of $\mathrm{C}^{14}$-labeled and $1.5 \mathrm{mg}$ of stable glucose per $\mathrm{ml}$. $\mathrm{TSH}, 1 \mathrm{U}, 4$ was added to each experimental vessel in $100 \mu \mathrm{l}$ of KRP, and a similar volume of KRP was added to the controls. Incubation was carried out at $38^{\circ} \mathrm{C}$ under 100 per cent oxygen in a Warburg apparatus. $\mathrm{CO}_{2}$ was absorbed by $300 \mu \mathrm{l}$ of 10 per cent $\mathrm{KOH}$ in a side-arm. Similar experimental conditions were employed to assess the effects of oxidized methylene blue (MB) on glucose metabolism.

Measurement of $I^{131}$-organification. After incubation, the reaction was stopped by chilling each vessel and adding $25 \mu 1$ of $0.08 \mathrm{M}$ methimazole. The percentile organification of iodide was usually determined by precipitation with trichloroacetic acid (TCA). Aliquots of homogenate $(20 \mu 1)$ were added to $0.7 \mathrm{ml}$ of a solution of human serum albumin $(1.4 \mathrm{~g}$ per $100 \mathrm{ml})$ in $13 \times 100 \mathrm{~mm}$ test tubes. Two $\mathrm{ml}$ of 10 per cent TCA was then added, the resulting precipitate was washed three times with 5 per cent TCA, dissolved in $2 \mathrm{~N} \mathrm{NaOH}$, and counted directly in a well-type scintillation counter. Pooled supernatants were alkalinized to prevent loss of iodide, diluted to standard volume and counted. Percentile organification was calculated according to the following formula:

rier compounds were then localized by spraying with diazotized sulfanilic acid for MIT and DIT, and with palladium chloride for iodide. For quantitative analysis, radioactive zones located by radioautography were cut from unstained chromatographic strips and were counted in a well-type scintillation counter.

In both chromatographic systems, three major zones of radioactivity were consistently seen in chromatograms of unhydrolyzed homogenate: a band at the point of application (origin material), a band coinciding with carrier inorganic iodide, and a less well defined band seen at the solvent front (front material). The latter comprised a variable proportion ( 30 to 60 per cent) of the non-inorganic $\mathrm{I}^{131}$. A band between iodide and front material, similar to the Unknown $2\left(\mathrm{U}_{2}\right)$, first described by Taurog, Tong and Chaikoff (8), was occasionally seen but never constituted a significant portion of the total $\mathrm{I}^{131}$. After tryptic hydrolysis of the homogenate, the radioactivity at the origin decreased and radioactivity appeared in the zone of carrier MIT. This indicated that the radioactive material at the origin was primarily protein containing MIT in peptide linkage. Unlike the origin material, iodinated material at the solvent front was readily eluted from chromatographic strips by chloroform, methanol, ether and butanol. Following rechromatography of the eluted front-running material, the radioactivity again appeared at the solvent front and coincided with an area which stained with Sudan black. These findings indicated that the frontrunning material was an iodinated lipid, suggesting that, 
in the homogenate system, oxidation of iodide results in the iodination of both proteins and lipid.

Chromatography was also performed to valiclate the use of TCA-precipitation as a measure of organified iodine. Direct chromatography of the TCA-precipitate showed radioactivity at both the origin and solvent front, but not in the iodide area. Chromatography of TCA-supernatants revealed only inorganic iodide. A chloroform: methanol extract of the TCA-precipitate contained only front-running material; the residual $\mathrm{I}^{131}$ in the precipitate was entirely composed of origin material. A saline extract of the precipitate showed only origin material. The ability to extract the front material prior to chromatography supported the conclusion that the front material was lipid iodinated in the homogenate, rather than a chromatographic artifact. Thus, both front and origin material appeared to be true products of iodination in the homogenate system. Since both were found in TCAprecipitates and not in supernatants, the precipitation technique could be considered as valid as chromatography for the assessment of the organification of radioiodide.

$\mathrm{C}^{14} \mathrm{O}_{2}$ production. The $\mathrm{C}^{14} \mathrm{O}_{2}$ evolved during incubation of tissues with labeled glucose was absorbed in $300 \mu \mathrm{l}$ of $\mathrm{KOH}$ in the side-arm of Warburg flasks. At the end of the incubation, tissues and media were removed and replaced by $2 \mathrm{ml}$ of $5 \mathrm{M} \mathrm{H}_{2} \mathrm{SO}_{4}$. Two hundred $\mu 1$ of 0.5 $\mathrm{M}$ Hyamine was placed in the center well and the flasks were tightly stoppered. The acid and alkali were then thoroughly mixed and the flasks were gently shaken at room temperature for 30 minutes. The Hyamine, now containing $\mathrm{CO}_{2}$ released from the alkali, together with several washes of the center well, was transferred to glass counting vials containing liquid scintillator. Samples were cooled overnight and then counted in an automatic liquid scintillation counter. An aliquot of the original incubation medium was counted as a standard. Internal standards were used to correct for variations in counting efficiency. The quantity of $\mathrm{C}^{14} \mathrm{O}_{2}$ produced was expressed as a per cent of added $\mathrm{C}^{14}$-labeled glucose per gram of tissue.

Miscellaneous methods. The reduction of added pyridine nucleotide coenzymes was assessed by measuring the optical density at $340 \mathrm{~m} \mu$ of supernatants obtained from $1: 3$ (vol/vol) mixtures of homogenate and 95 per cent ethanol (9). When necessary, Celite was added as a clearing agent. Analyses for stable glucose were performed by an enzymatic method (10).

\section{RESULTS}

Duplicate or triplicate vessels were incubated in all experiments. Results presented represent the mean of individual determinations, which, with few exceptions, agreed closely.

\section{Organic iodinations}

Anoxia (Table I). Despite wide variations in percentile iodinations obtained in control vessels,
TABLE I

The effect of anoxia on organic iodinations in plain and supplemented homogenates of sheep thyroid glands

\begin{tabular}{|c|c|c|c|}
\hline \multirow{2}{*}{$\begin{array}{l}\text { Expt. } \\
\text { no. }\end{array}$} & \multirow{2}{*}{$\begin{array}{c}\text { Compound } \\
\text { added* }\end{array}$} & \multicolumn{2}{|c|}{ Organic $I^{131}$} \\
\hline & & $\mathrm{O}_{2}$ & $\mathrm{~N}_{2}$ \\
\hline & & \multicolumn{2}{|c|}{$\%$ total } \\
\hline 4 & 0 & 8.4 & 0.8 \\
\hline 15 & 0 & 1.6 & 0.5 \\
\hline 18 & 0 & 3.9 & 0.5 \\
\hline \multirow[t]{2}{*}{24} & 0 & 3.1 & 0.6 \\
\hline & DPN & 2.8 & 0.5 \\
\hline \multirow[t]{4}{*}{33} & 0 & 2.4 & 0.5 \\
\hline & DPN & 2.3 & 0.4 \\
\hline & TPN & 3.7 & 0.4 \\
\hline & TPNH & 3.2 & \\
\hline \multirow[t]{3}{*}{110} & 0 & 0.9 & 0.3 \\
\hline & FAD & 1.3 & 0.4 \\
\hline & $\mathrm{TPN}+\mathrm{FAD}$ & 6.2 & 0.6 \\
\hline \multirow[t]{3}{*}{34} & 0 & 11.1 & 0.4 \\
\hline & $\mathrm{CuCl}_{2}$ & 39.8 & 0.9 \\
\hline & $\mathrm{HgCl}_{2}$ & 33.0 & 1.8 \\
\hline 42 & MB & 5.5 & 0.3 \\
\hline
\end{tabular}

* Compounds added to a final concentration of $0.0007 \mathrm{M}$, except in the following instances: $\mathrm{CuCl}_{2}, 0.0125 \mathrm{M} ; \mathrm{HgCl}_{2}$, $0.0005 \mathrm{M} ; \mathrm{MB}, 0.00018 \mathrm{M}$.

organic iodinations were markedly depressed by anaerobic incubation. Comparable inhibition of iodination was effected by anoxia, even in the presence of factors which were highly stimulatory to iodinations when oxygen was present. At lower partial pressures, the system was especially sensitive to the partial pressure of oxygen, but maximal rates of iodination were not achieved until the atmosphere was 100 per cent oxygen (Figure 1).

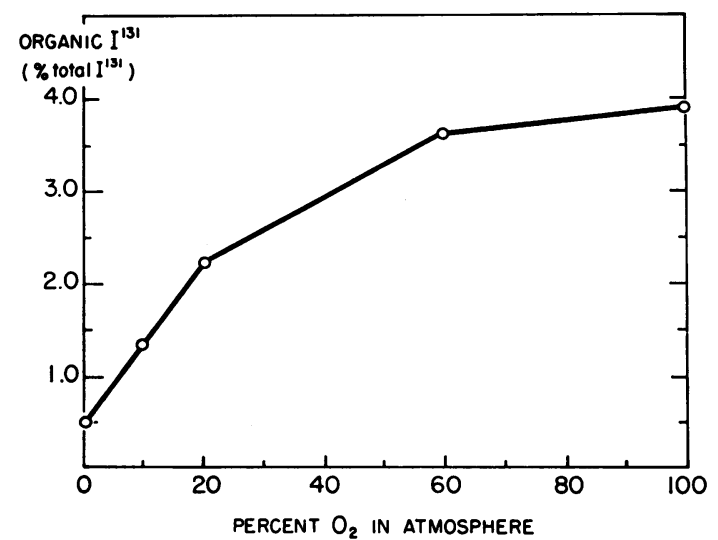

Fig. 1. The efFect of varying OXYGen tensions on ORGANIC IODINATIONS IN A HOMOGENATE OF SHEEP THYROID GLANDS. 
TABLE II

The effects of dialysis and storage on organic iodinations in homogenates of sheep thyroid glands *

\begin{tabular}{cccc}
\hline \hline & \multicolumn{3}{c}{ Organic $\mathrm{I}^{131}$} \\
\cline { 2 - 4 } & Control & Dialyzed & Stored \\
\hline & \% total & \% total & \% total \\
1 & 1.3 & 8.2 & 2.9 \\
3 & 4.9 & 11.3 & 7.8 \\
4 & 8.4 & 29.2 & 9.4 \\
9 & 5.4 & 30.0 & \\
$9 \mathrm{a} \dagger$ & 3.3 & 25.0 & \\
16 & 1.3 & 13.9 & \\
18 & 3.9 & & 4.5 \\
22 & 1.1 & 2.1 & \\
$22 \mathrm{a} \dagger$ & 0.9 & 1.7 & \\
26 & 2.8 & 13.5 & 3.7 \\
60 & 2.7 & 22.2 & \\
63 & 3.3 & 2.2 & \\
68 & 1.5 & 20.9 & \\
69 & 1.9 & 24.4 &
\end{tabular}

* An aliquot of the control homogenate either stored or dialyzed for 16 hours against $25 \mathrm{vol}$ of homogenization medium at $4^{\circ} \mathrm{C}$ prior to incubation with inorganic $I^{131}$.

$t$ Glucose-6-phosphate $(0.015 \mathrm{M})$ added to control and dialyzed homogenates prior to incubation.

Dialysis and storage (Table II). Dialysis of homogenate for 16 hours at $4^{\circ} \mathrm{C}$ against $24 \mathrm{vol}$ of the homogenization medium consistently increased the percentage of added $\mathrm{I}^{131}$ organified. In 12 experiments, percentile iodinations in dialyzed homogenates averaged 650 per cent of the values obtained the day before in undialyzed controls. Iodinations in homogenates stored at $4^{\circ} \mathrm{C}$ for the same period of time were also consistently, although less markedly, stimulated.

Sulfhydryl inhibitors. The addition of $\mathrm{CuCl}_{2}$ markedly stimulated organic iodinations. In eight experiments, iodinations in the presence of $\mathrm{CuCl}_{2}$ $(0.0125 \mathrm{M})$ averaged 692 per cent of control values. In four experiments, performed in the same homogenates before and after dialysis, the stimulatory effect of $\mathrm{CuCl}_{2}$ was abolished or greatly diminished in the dialyzed samples (Table III).

The addition of $\mathrm{HgCl}_{2}$ also produced a pronounced stimulation of iodinations which was abolished by prior dialysis of the homogenate (Table III).

NEM, a specific sulfhydryl inhibitor (11), was stimulatory at concentrations between $2 \times 10^{-4}$ and $10^{-3} \mathrm{M}$; higher concentrations were inhibitory (Figure 2). After dialysis of the homogenate, stimulatory effects of NEM were diminished or changed to inhibition (Figure 3 ).

Glutathione. Iodinations in the homogenate
TABLE III

The effects of heavy metals on organic iodinations in homogenates of sheep thyroid glands

\begin{tabular}{|c|c|c|c|}
\hline \multirow{2}{*}{$\begin{array}{l}\text { Expt. } \\
\text { no. }\end{array}$} & \multirow{2}{*}{$\begin{array}{l}\text { Concen- } \\
\text { tration }\end{array}$} & \multicolumn{2}{|c|}{ Organic I'131 } \\
\hline & & Control & Inhibitor \\
\hline $\mathrm{CuCl}_{2}$ & $M$ & \multicolumn{2}{|c|}{$\%$ total } \\
\hline & 0.0125 & 11.1 & 39.8 \\
\hline 66 & 0.0125 & 9.0 & 20.2 \\
\hline 76 & 0.0125 & 2.3 & 24.0 \\
\hline 79 & 0.0125 & 2.8 & 26.6 \\
\hline 109 & 0.0125 & 3.6 & 14.7 \\
\hline \multirow[t]{3}{*}{4} & 0.0025 & 8.4 & 8.3 \\
\hline & 0.0040 & 8.4 & 14.0 \\
\hline & 0.040 & 8.4 & 7.2 \\
\hline \multirow{3}{*}{$\begin{array}{l}4-D^{*} \\
26\end{array}$} & 0.0040 & 29.2 & 17.0 \\
\hline & 0.0005 & 2.8 & 3.2 \\
\hline & $\begin{array}{l}0.0025 \\
0.0125\end{array}$ & $\begin{array}{l}2.8 \\
2.8\end{array}$ & $\begin{array}{r}8.3 \\
16.6\end{array}$ \\
\hline 26-D & $\begin{array}{l}0.0125 \\
0.0125\end{array}$ & $\begin{array}{r}2.8 \\
13.5\end{array}$ & 11.3 \\
\hline 68 & 0.0125 & 1.5 & 13.9 \\
\hline 68-D & 0.0125 & 20.9 & 31.6 \\
\hline 69 & 0.0125 & 1.9 & 18.3 \\
\hline 69-D & 0.0125 & 24.4 & 31.4 \\
\hline \multicolumn{4}{|l|}{$\mathrm{HgCl}_{2}$} \\
\hline 34 & 0.0005 & 11.1 & 33.0 \\
\hline \multirow[t]{3}{*}{26} & 0.0005 & 2.8 & 27.1 \\
\hline & 0.0025 & 2.8 & 4.7 \\
\hline & 0.0125 & 2.8 & 3.2 \\
\hline 26-D & 0.0005 & 13.5 & 12.6 \\
\hline
\end{tabular}

* D indicates homogenate dialyzed against $25 \mathrm{vol}$ of homogenization medium for 16 hours at $4^{\circ} \mathrm{C}$ prior to addition of inhibitor and incubation with $\mathrm{I}^{131}$. Effects of inhibitor had also been tested in the same homogenate prior to dialysis.

system were inhibited by the addition of glutathione. When compared in the same homogenates, $0.02 \mathrm{M} \mathrm{GSH}$ was more inhibitory than an equivalent concentration of GSSG. In other experi-

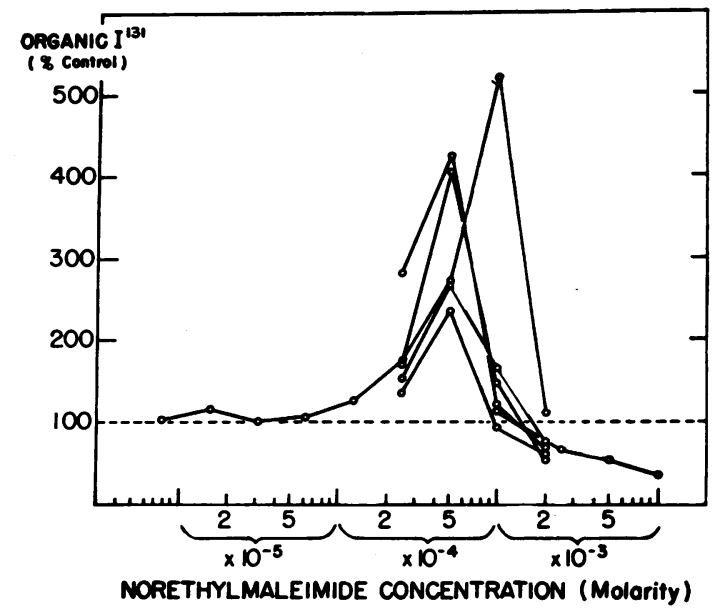

Fig. 2. The efFect of varying concentrations of A SULFHYDRYL INHIBITOR, NORETHYLMALEIMIDE, ON ORGANIC IODINATIONS IN HOMOGENATES OF SHEEP THYROID GLANDS. 


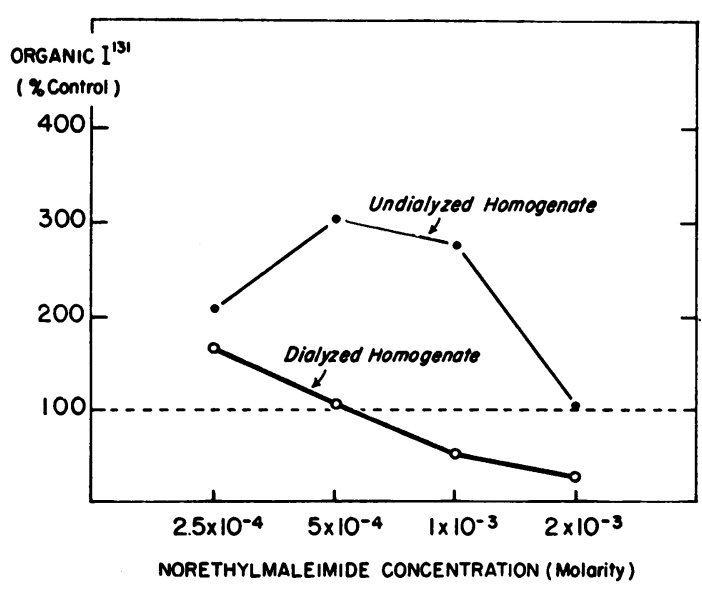

Fig. 3. THE EFFECT OF DIALYSis OF SHEeP THYROID HOMOGENATES ON THE RESPONSE OF ORGANIC IODINATIONS TO THE ADDITION OF NORETHYLMALEIMIDE. Iodinations were measured prior to and following dialysis of homogenate at $4^{\circ} \mathrm{C}$ against 24 vol of homogenization medium for 16 hours. In each instance, the control value is that obtained in appropriately treated homogenate not supplemented with norethylmaleimide.

ments, the inhibitory effect of GSSG was inconstant. However, when TPN $\left(7 \times 10^{-4} \mathrm{M}\right)$ was added, iodinations in the presence of GSSG were more often lower than those found in control, unsupplemented vessels (Figure 4). The consistent and pronounced inhibitory effect of GSSG

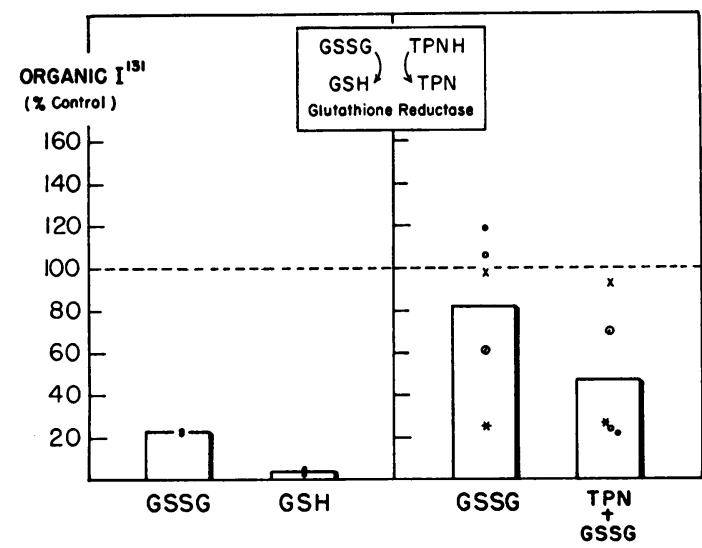

Fig. 4. EFFeCt of OXIDized AND REdUCEd GLUTATHIONE ON ORGANIC IODINATIONS IN SHEEP THYROID HOMOGENATES AND THE EFFECT OF ADDED TPN ON THE RESPONSE to oxidized GLUTATHione. Oxidized and reduced glutathione are compared directly in two experiments, as shown on the left. Enhancement of the response to oxidized glutathione by TPN is shown on the right. Each symbol represents results obtained in an individual experiment. Schema in enclosed box depicts enzymatic pathway for the reduction of oxidized glutathione.

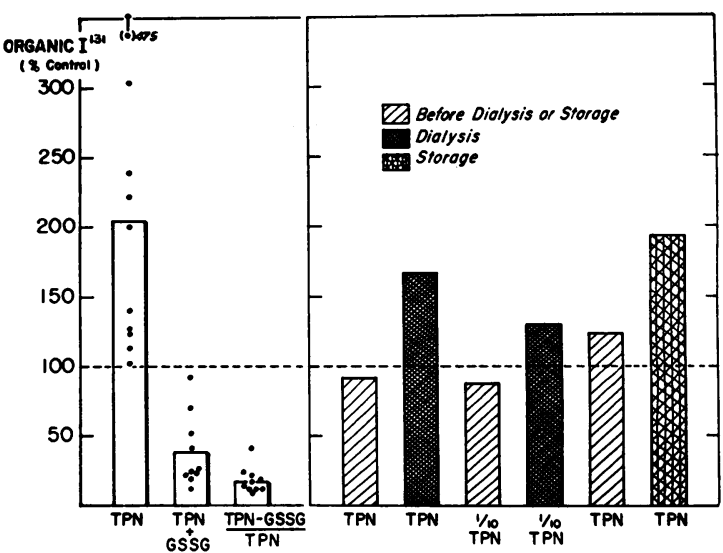

Fig. 5. Modification of the TPN efFect ON ORGANIC IODINATIONS BY GLUTATHIONE AND BY A LABILE ENDOGENous INHIBIToR. Shown on the left are results of ten experiments in which the effects of TPN, with and without added oxidized glutathione, were compared. TPNGSSG/TPN represents ratio of iodinations obtained in the same homogenate under the two conditions, expressed as a per cent. On the right are shown effects of dialyzing or storing homogenates on the response to TPN. Dialysis experiment performed in a single homogenate; storage experiment in another. Values expressed as a per cent of control value obtained in either fresh, dialyzed or stored homogenates, not supplemented with TPN.

in the presence of TPN was best demonstrated, however, when iodinations in vessels containing both cofactors were compared with those obtained with TPN alone (Figure 5).

Glycolytic substrates (Table IV). A number of substrates was tested. The addition of succinate consistently stimulated iodination. Other substrates did not seem to have a marked or consistent effect.

Pyridine nucleotide coenzymes. Both TPN $\left(7 \times 10^{-4} \mathrm{M}\right)$ and DPN $\left(7 \times 10^{-4} \mathrm{M}\right)$ usually stimulated iodinations when added to thyroid homogenates (Figure 6). In 45 experiments, organic iodinations in TPN-enriched homogenates averaged 182 per cent of control values. The effect of DPN was less marked and less consistent. In 24 experiments DPN increased iodinations by an average of only 27 per cent, and in 7 of these experiments there was no stimulatory effect. The impression that the effect of TPN was more pronounced than that of DPN was confirmed by comparing effects of the coenzymes in the same homogenate. In each of 20 such experiments, TPN was the more stimulatory and mean iodination in TPN-supplemented flasks was 153 per cent of 
TABLE IV

The effects of glycolytic substrates on organic iodinations in homogenates of sheep thyroid glands

\begin{tabular}{|c|c|c|c|}
\hline \multirow{2}{*}{$\begin{array}{c}\text { Expt. } \\
\text { no. }\end{array}$} & \multirow[b]{2}{*}{ Substrate* } & \multicolumn{2}{|c|}{ Organic $\mathrm{I}^{131}$} \\
\hline & & Control & Substrate \\
\hline & & \multicolumn{2}{|c|}{$\%$ total } \\
\hline 31 & Glucose & 3.0 & 2.7 \\
\hline 32 & Glucose & 1.7 & 1.9 \\
\hline 4 & G-6-P & 8.4 & 5.1 \\
\hline 9 & $\mathrm{G}-6-\mathrm{P}$ & 5.4 & 3.3 \\
\hline 9-D & G-6-P & 30.0 & 25.0 \\
\hline 22 & G-6-P & 0.9 & 1.1 \\
\hline 38 & G-6-P & 1.8 & 2.0 \\
\hline 39 & $\mathrm{G}-6-\mathrm{P}$ & 2.5 & 2.3 \\
\hline 35 & Fructose & 1.1 & 0.8 \\
\hline 58 & Pyruvate & 17.6 & 18.2 \\
\hline $37-\mathrm{D}$ & Citrate & 58.6 & 60.1 \\
\hline 58 & Citrate & 17.6 & 15.2 \\
\hline 40 & Isocitrate & 0.6 & 1.0 \\
\hline 40 & $\alpha$-Ketoglutarate & 0.6 & 0.6 \\
\hline 38 & Succinate & 1.8 & 3.1 \\
\hline 39 & Succinate & 2.5 & 3.7 \\
\hline 40 & Oxaloacetate & 0.6 & 0.8 \\
\hline 58 & Oxaloacetate & 17.6 & 21.9 \\
\hline
\end{tabular}

* All substrate added to a final concentration of $0.02 \mathrm{M}$ except glucose-6-phosphate, which was added to a final concentration of $0.015 \mathrm{M}$.

that obtained in vessels supplemented with DPN. The rate of reduction of added TPN in a homogenate containing G-6-P is compared to the rate of organic iodinations in Figure 7. Following the addition of TPN, the concentration of TPNH rapidly increased, reaching a virtually constant value within 5 minutes. Iodinations, however, continued at an accelerated rate for the remainder of the experiment. Although a second addition of TPN again resulted in a rapid increase in the

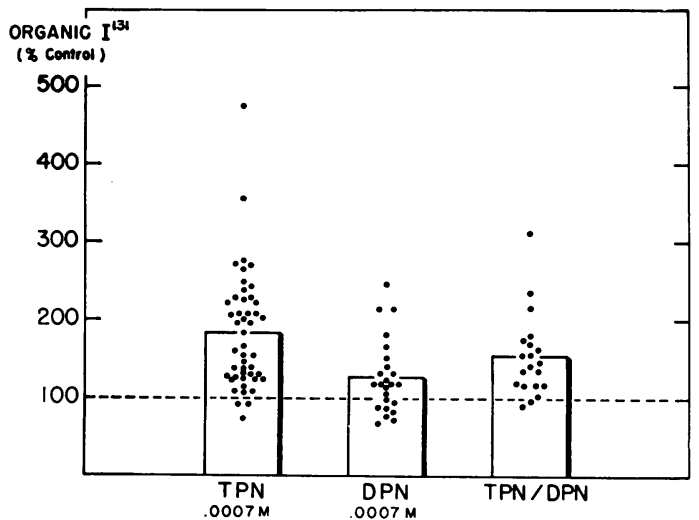

Fig. 6. Effects of TPN and DPN on organic ioDINATIONS IN SHEEP THYROID HOMOGENATES. TPN/DPN represents ratio, expressed as per cent, of values found in 20 experiments in which effects of TPN and DPN were compared in the same homogenate.
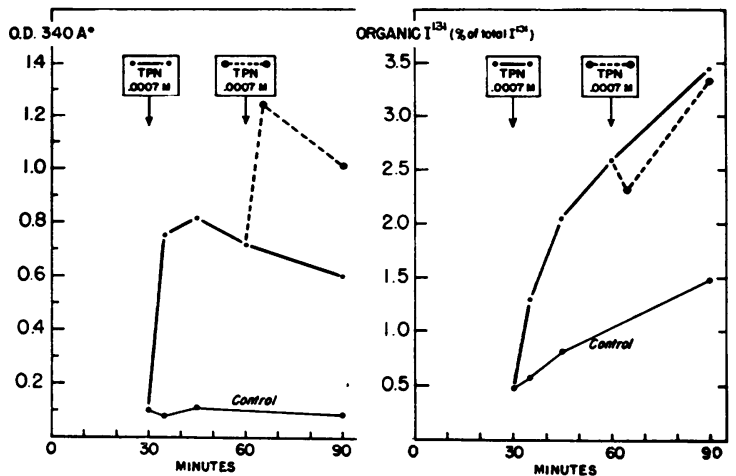

Fig. 7. The Relation between organic iodinations AND THE REDCCTION OF TPN IN A SHEEP THYROID HOMOGENATE. At the indicated times, TPN tipped into homogenates from the side-arm of Warburg vessels in quantities sufficient to enhance the concentration of TPN by $0.0007 \mathrm{M}$.

concentration of TPNH, there was no further stimulation of iodinations. Following the addition of comparable concentrations of DPN, the increase in concentration of DPNH was far less than had been the case with TPN.

The effects of TPN and DPN were modified by supplementing homogenates with reducirg systems specifically requiring one of the coenzymes

TABLE V

Modification of the stimulatory effects of pyridine nucleotide coenzymes on organic iodinations by the addition of their specific reducing systems

\begin{tabular}{llc}
\hline \multicolumn{1}{c}{ Compound added } & Concentration* & $\begin{array}{c}\text { Percentile } \\
\text { organic } \\
\text { iodinations } \\
\text { (\% control } \\
\text { iodinations) }\end{array}$ \\
\hline DPN & 0.0007 & 118 \\
DPN & 0.0007 & 95 \\
Ethanol & 0.01 & \\
DPN & 0.0007 & \\
Ethanol & 0.01 & 87 \\
Alcohol dehydrogenase & 0.023 & \\
TPN & 0.0007 & 127 \\
Isocitrate & 0.02 & 121 \\
Isocitric dehydrogenase & 1.0 & 100 \\
TPX & 0.0007 & \\
Isocitrate & 0.02 & 152 \\
Isocitrate dehydrogenase & 1.0 &
\end{tabular}

* Molar concentrations of all compounds except alcohol and isocitric dehydrogenases, for which concentrations given represent $\mathrm{mg} / \mathrm{ml}$ homogenate.

$\dagger$ Cryst. from yeast, Sigma Chemical Co., 100 to 150,000 $\mathrm{U} / \mathrm{mg}$.

$\ddagger$ Type I, crude, Sigma Chemical Co., $30 \mathrm{U} / \mathrm{mg}$. 


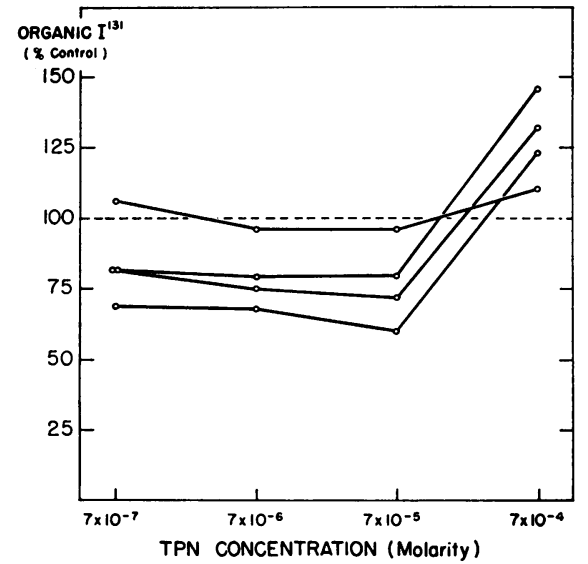

Fig. 8. The efFects of Varying concentrations OF TPN ON ORGANIC IODINATIONS IN SHEEP THYROID HOMOGENATES.

as hydrogen acceptor. The addition of isocitric acid and isocitric dehydrogenase potentiated the stimulatory effect of TPN on iodinations; the addition of ethyl alcohol plus alcohol dehydrogenase changed the stimulatory effect of DPN to a moderate inhibition. Similar results were obtained in several experiments, one of which is shown in Table V.

When added to the same homogenates in which the usual concentration of TPN $\left(7 \times 10^{-4} \mathrm{M}\right)$ was stimulatory, lower concentrations of TPN $(7 \times$ $10^{-5}$ to $7 \times 10^{-7} \mathrm{M}$ ) failed to stimulate iodinations and, indeed, were moderately inhibitory (Figure 8). The effects of DPN $\left(7 \times 10^{-4} \mathrm{M}\right)$, and of TPN at 0.1 its usual concentration (i.e., $7 \times 10^{-5}$ $\mathrm{M})$, alone and in combination, are compared in

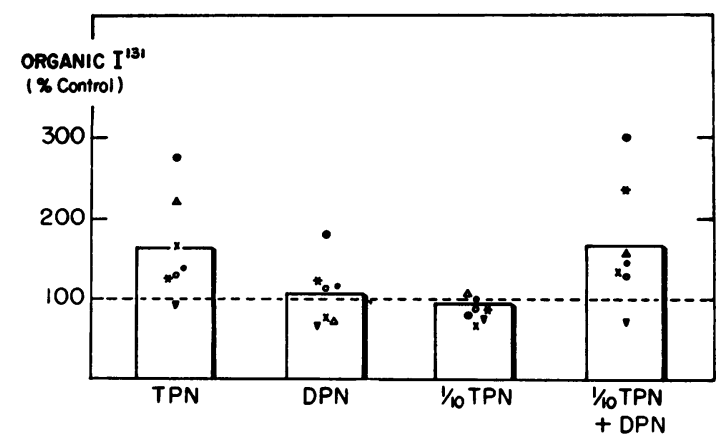

Fig. 9. Synergistic effects of TPN and DPN on ORGANIC IODINATIONS IN SHEEP THYROID HOMOGENATES. TPN and DPN, final concentration 0.0007 M.; $0.1 \mathrm{TPN}$, final concentration $0.00007 \mathrm{M}$. Each symbol represents results obtained in a single experiment.
Figure 9. The addition of both coenzymes produced a stimulation greater than that expected from the sum of their individual effects, and iodinations were then usually equal to or greater than those obtained with the higher concentrations of TPN alone.

Prior dialysis of homogenates altered the response to TPN. Representative results are shown in Figure 5. In a homogenate in which the full concentration of TPN $\left(7 \times 10^{-4} \mathrm{M}\right)$ was not stimulatory prior to dialysis, stimulation was produced by TPN after the homogenate had been dialyzed. The usual inhibitory effect of lower concentrations of TPN $\left(7 \times 10^{-5} \mathrm{M}\right)$ was also changed to stimulation by dialysis. In separate experiments, a similar potentiation of the response to TPN was achieved by storage.

When TPN $\left(7 \times 10^{-4} \mathrm{M}\right)$ was added to homogenates containing stimulatory concentrations of NEM, the resulting increase in iodinations was considerably greater than the stimulation produced by the addition of TPN alone (Figure 10). Even concentrations of TPN which were inhibitory when added alone $\left(7 \times 10^{-5} \mathrm{M}\right)$ became stimulatory when added together with NEM. The addition of GSSG abolished the stimulatory effect of TPN and produced a consistent inhibition of iodinations, as compared with iodinations obtained in vessels supplemented with TPN alone (Figure 5).

Methylene blue (Table VI). In seven separate homogenates to which $\mathrm{MB}\left(1.8 \times 10^{-4} \mathrm{M}\right)$ was added, iodinations were increased by an average of 94 per cent. The addition of TPN

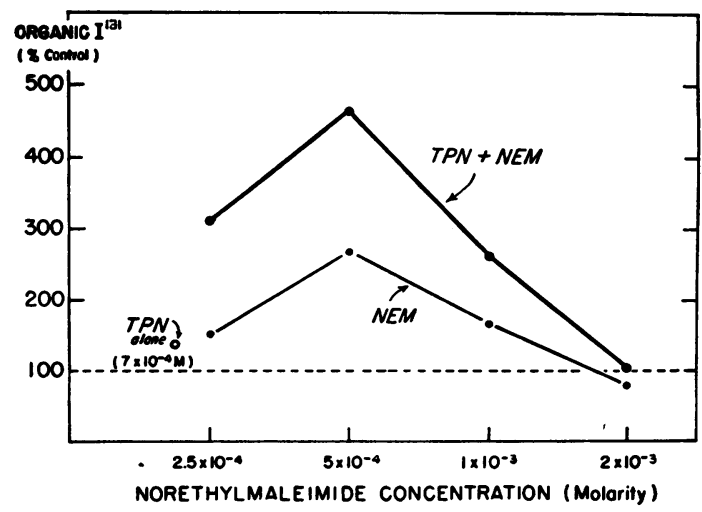

Fig. 10. The efFect of TPN AND NOREThylmaleiMIDE, ALONE AND IN COMBINATION, ON ORGANIC IODINATIONS IN A SHEEP THYROID HOMOGENATE. 
TABLE VI

The effects of methylene blue and cytochrome $C$ on organic iodinations in homogenates of sheep thyroid glands

\begin{tabular}{ccc}
\hline & \multicolumn{2}{c}{ Organic I'131 } \\
\cline { 2 - 3 } Expt. no. & Control & $\begin{array}{c}\text { Compound } \\
\text { added }\end{array}$ \\
\hline \multicolumn{3}{c}{ \% total } \\
Methylene blue (0.00018 M) & \\
42 & 2.5 & 5.5 \\
$42 \mathrm{a}^{*}$ & 5.2 & 10.1 \\
45 & 1.3 & 3.5 \\
66 & 9.0 & 11.9 \\
68 & 1.5 & 2.2 \\
$68-\mathrm{D} \dagger$ & 20.9 & 38.6 \\
69 & 1.9 & 4.8 \\
$69-\mathrm{D}$ & 24.4 & 32.2 \\
76 & 2.3 & 4.4 \\
78 & 3.5 & 5.1
\end{tabular}

Cytochrome C (0.0007 M)

$\begin{array}{lrr}57 & 2.4 & 1.6 \\ 68 & 1.5 & 2.1 \\ 68-D & 20.9 & 26.4 \\ 69 & 1.9 & 1.8 \\ 69-D & 24.4 & 24.7 \\ 76 & 2.3 & 3.7\end{array}$

* Homogenate supplemented with TPN $(0.0007 \mathrm{M})$

$\dagger \mathrm{D}$ indicates homogenates dialyzed against $25 \mathrm{vol}$ of homogenization medium for 16 hours at $4^{\circ} \mathrm{C}$ prior to addition of compound and incubation with $\mathrm{I}^{131}$. Effects of compound also tested in same homogenate prior to dialysis.

with MB produced a further stimulation of iodinations.

Flavin coenzymes. FAD had a weak and inconstant stimulatory effect, producing an average increase of 22 per cent in organic iodinations in seven experiments. In the same homogenates,

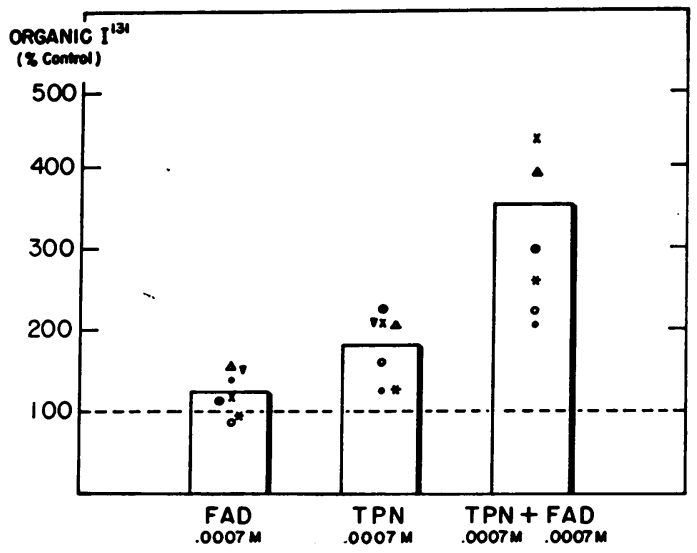

Fig. 11. Synergistic efFects OF TPN ANd FAD on ORGANIC IODINATIONS IN SHEEP THYROID HOMOGENATES. Concentrations shown represent final concentration of added compound in homogenate. Each symbol represents the results of an individual experiment.
TABLE VII

The effect of light on organification of $I^{131}$ in a solution of human serum albumin and in a homogenate of sheep thyroid glands

\begin{tabular}{|c|c|c|c|c|}
\hline \multirow{2}{*}{$\begin{array}{l}\text { Expt. } \\
\text { no. }\end{array}$} & \multirow{2}{*}{$\begin{array}{l}\text { Cofactor } \\
\text { added* }\end{array}$} & \multirow{2}{*}{$\begin{array}{l}\text { Conditions } \\
\text { of } \\
\text { experiment }\end{array}$} & \multicolumn{2}{|c|}{ Organic $I^{131}$} \\
\hline & & & No cofactor & Cofactor \\
\hline & & & \multicolumn{2}{|c|}{$\%$ total } \\
\hline \multicolumn{5}{|c|}{ Incubation in human serum albumin $(2.5 \mathrm{~g} / 100 \mathrm{ml})$} \\
\hline 100 & $\begin{array}{l}\text { FAD } \\
\text { FMN } \\
\text { FAD } \\
\text { FMN }\end{array}$ & $\begin{array}{l}\text { Dark } \\
\text { Dark } \\
\text { Light } \\
\text { Light }\end{array}$ & $\begin{array}{l}2.0 \\
2.0 \\
2.7 \\
2.7\end{array}$ & $\begin{array}{l}2.1 \\
2.6 \\
4.1 \\
6.9\end{array}$ \\
\hline 108 & $\begin{array}{l}\text { TPN } \\
\text { FAD } \\
\text { TPN +FAD } \\
\text { TPN } \\
\text { FAD } \\
\text { TPN +FAD }\end{array}$ & $\begin{array}{l}\text { Light } \\
\text { Light } \\
\text { Light } \\
\text { Light-N } N_{2} \dagger \\
\text { Light-N } N_{2} \\
\text { Light-N2 }\end{array}$ & $\begin{array}{l}0.8 \\
0.8 \\
0.8 \\
0.6 \\
0.6 \\
0.6\end{array}$ & $\begin{array}{l}0.7 \\
2.8 \\
2.2 \\
0.6 \\
1.0 \\
0.8\end{array}$ \\
\hline \multicolumn{5}{|c|}{ Incubation in thyroid homogenate } \\
\hline 110 & $\begin{array}{l}\text { TPN } \\
\text { TPN } \\
\text { FAD } \\
\text { FAD } \\
\text { TPN +FAD } \\
\text { TPN +FAD } \\
\text { FAD +FAD } \\
\text { TPN +FAD }\end{array}$ & $\begin{array}{l}\text { Dark } \\
\text { Light } \\
\text { Dark } \\
\text { Light } \\
\text { Dark } \\
\text { Light } \\
\text { Light-N2 } \\
\text { Light-N2 }\end{array}$ & $\begin{array}{l}0.9 \\
0.7 \\
0.9 \\
0.7 \\
0.9 \\
0.7 \\
0.3 \\
0.3\end{array}$ & $\begin{array}{l}1.9 \\
1.9 \\
1.3 \\
2.6 \\
5.8 \\
6.2 \\
0.4 \\
0.6\end{array}$ \\
\hline
\end{tabular}

* Cofactors added to a final concentration of $0.0007 \mathrm{M}$. $+\mathrm{N}_{2}$ indicates incubations performed in atmosphere of $100 \%$ nitro$\dagger \mathrm{N}_{2}$ indicates incubations performed in at
gen. All others performed in $100 \%$ oxygen.

TPN alone increased iodinations by an average of 80 per cent. However, when the two coenzymes were added together, iodinations were increased by 252 per cent (Figure 11). In a single experiment, FMN stimulated iodinations moderately.

Cytochrome C (Table VI). Cytochrome $\mathrm{C}$ had only a slight or inconstant effect on organic iodinations, whether added alone or with other cofactors.

Effects of light (Table VII). Iodinations in the tissue-free system were markedly increased by the addition of FAD or FMN when flasks were incubated in room light reinforced by an ultraviolet lamp. This effect was greatly diminished by the exclusion of light or oxygen. Even in the presence of light and oxygen, TPN did not stimulate iodinations in the tissue-free system, nor did it enhance the stimulatory effect of FAD.

In thyroid homogenates, the presence or absence of light had no effect upon control iodinations. The increase in iodinations which followed the addition of FAD was partially inhibited in the dark. On the other hand, the increase in organic iodinations due to TPN, as well as the marked synergism between TPN and FAD, was unaffected by the presence or absence of light.

Metabolic inhibitors (Table VIII). $\mathrm{KCN}$ inhibited organic iodinations. Antimycin A had a very slight stimulatory effect when added alone 
TABLE VIII

The effect of metabolic inhibitors and antithyroid agents on organic iodinations in homogenates of sheep thyroid glands

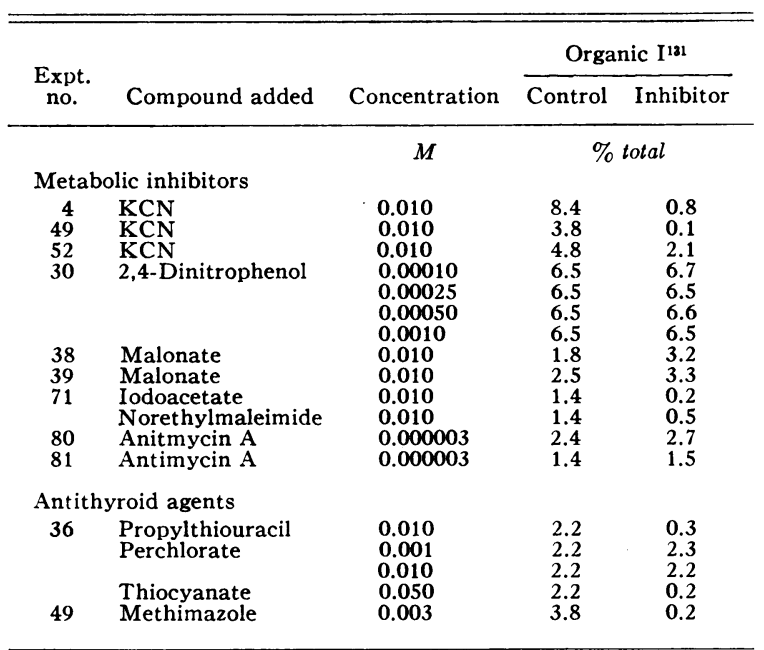

or together with TPN or DPN. Dinitrophenol had no effect. In two experiments, malonate $(0.02 \mathrm{M})$ stimulated iodinations.

Antithyroid drugs (Table VIII). Methimazole, propylthiouracil and thiocyanate greatly inhibited iodinations; perchlorate had no effect.

\section{Glucose metabolism}

The effect on glucose metabolism of various factors which stimulate organic iodinations is

TABLE IX

The effect of factors stimulatory to organic iodinations on the production of carbon dioxide from glucose of homogenates of sheep thyroid glands

\begin{tabular}{|c|c|c|c|c|c|}
\hline \multirow{3}{*}{$\begin{array}{l}\text { Expt. } \\
\text { no. }\end{array}$} & \multirow{3}{*}{$\begin{array}{l}\text { Compound } \\
\text { added }\end{array}$} & \multicolumn{4}{|c|}{$\begin{array}{l}\mathrm{C}^{14} \mathrm{O}_{2} \text { production (\% added } \\
\text { glucose } / \mathrm{g} \text { tissue) }\end{array}$} \\
\hline & & \multicolumn{2}{|c|}{ Control } & \multicolumn{2}{|c|}{ Compound added } \\
\hline & & $1-\mathrm{C}^{14} \mathrm{O}_{2}$ & 6- $\mathrm{C}^{14} \mathrm{O}_{2}$ & $1-\mathrm{C}^{14} \mathrm{O}_{2}$ & $6-\mathrm{C}^{14} \mathrm{O}_{2}$ \\
\hline \multirow[t]{2}{*}{96} & DPN & 0.09 & 0.01 & 2.33 & 0.18 \\
\hline & DPN + TPN* & 0.09 & 0.01 & 6.94 & \\
\hline \multirow[t]{4}{*}{97} & DPN & 0.14 & 0.02 & 1.57 & 0.04 \\
\hline & TPN & 0.14 & 0.02 & 1.41 & 0.12 \\
\hline & TPN* & 0.14 & 0.02 & 0.31 & 0.02 \\
\hline & $\mathrm{DPN}+\mathrm{TPN} *$ & 0.14 & 0.02 & 8.70 & 0.08 \\
\hline 101 & DPN & 0.23 & 0.01 & 1.64 & 0.02 \\
\hline \multirow{3}{*}{102} & TPN & 0.44 & 0.10 & 0.82 & 0.16 \\
\hline & FAD & 0.44 & 0.10 & 0.58 & 0.15 \\
\hline & $\mathrm{TPN}+\mathrm{FAD}$ & 0.44 & 0.10 & 9.10 & 0.25 \\
\hline \multirow[t]{3}{*}{103} & TPN & 0.08 & 0.01 & 0.47 & 0.05 \\
\hline & TPN +FAD & 0.08 & 0.01 & 10.08 & 0.12 \\
\hline & $\mathrm{TPN}+\mathrm{FMN}$ & 0.08 & 0.01 & 10.77 & 0.17 \\
\hline \multirow[t]{2}{*}{105} & TPN & 0.49 & 0.07 & 3.86 & 0.04 \\
\hline & TPN +FAD & 0.49 & 0.07 & 3.67 & 0.07 \\
\hline \multirow[t]{2}{*}{106} & TPN & 0.09 & 0.03 & 0.40 & 0.04 \\
\hline & TPN + FAD & 0.09 & 0.03 & 0.93 & 0.02 \\
\hline \multirow[t]{2}{*}{101} & $\mathrm{CuCl}_{2} *$ & 0.23 & 0.01 & 0.03 & 0.02 \\
\hline & $\mathrm{HgCl}_{2} *$ & 0.23 & 0.01 & 0.02 & 0.00 \\
\hline
\end{tabular}

* Asterisk indicates TPN, $1 \times 10^{-5} \mathrm{M} ; \mathrm{CuCl}_{2}, 12.5 \times 10^{-3} \mathrm{M} ; \mathrm{HgCl}_{2}$, $5 \times 10^{-4} \mathrm{M}$. All other concentrations, $7 \times 10^{-4} \mathrm{M}$. shown in Table IX. As compared with slices, unsupplemented homogenates metabolized glucose to $\mathrm{CO}_{2}$ at a relatively slow rate. During 1 hour of incubation, the $\mathrm{C}^{14} \mathrm{O}_{2}$ recovered from glucose labeled in the 1 and 6 positions $\left(1-\mathrm{C}^{14} \mathrm{O}_{2}\right.$ and 6- $\mathrm{C}^{14} \mathrm{O}_{2}$ ) averaged 0.23 and 0.04 per cent per $\mathrm{g}$ of tissue, respectively, in eight experiments. In seven experiments with slices incubated for a comparable period, the production of $1-\mathrm{C}^{14} \mathrm{O}_{2}$ averaged 3.86 per cent and $6-\mathrm{C}^{14} \mathrm{O}_{2} 1.53$ per cent of added $\mathrm{C}^{14}$ labeled glucose per $\mathrm{g}$ of tissue.

Pyridine nucleotide coenzymes. Both DPN and TPN stimulated the production of $\mathrm{C}^{14} \mathrm{O}_{2}$ from labeled glucose. In six experiments, TPN stimulated the production of $1-\mathrm{C}^{14} \mathrm{O}_{2}$ by an average of 756 per cent and the production of 6- $\mathrm{C}^{14} \mathrm{O}_{2}$ by an average of 200 per cent. DPN, in three experiments, stimulated $1-\mathrm{C}^{14} \mathrm{O}_{2}$ by an average of 1,233 per cent and $6-\mathrm{C}^{14} \mathrm{O}_{2}$ by 800 per cent. In two experiments, the effects of full concentrations $\left(7 \times 10^{-4} \mathrm{M}\right)$ of TPN and DPN were compared in the same homogenate. In one of these, the stimulatory effects of the coenzymes were essentially the same. In the second experiment, in which iodinations were also measured, TPN caused a greater increase in the production of $1-\mathrm{C}^{14} \mathrm{O}_{2}$ than did DPN. In this experiment, iodinations were slightly stimulated by TPN and were unaffected by DPN.

The interaction of DPN with TPN at 0.1 its usual concentration (i.e., $7 \times 10^{-5} \mathrm{M}$ ) was also evaluated in two experiments. In both, the lower concentration of TPN stimulated $1-\mathrm{C}^{14} \mathrm{O}_{2}$ pro-

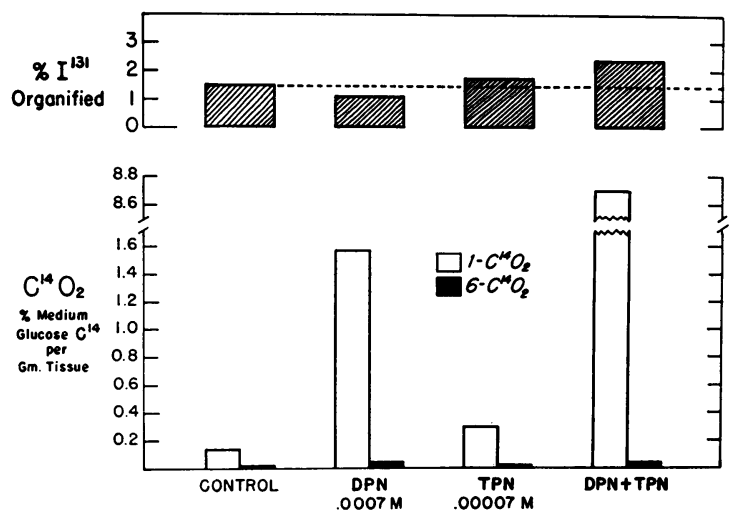

Fig. 12. The effects of TPN and DPN, alone and in COMBINATION, ON ORGANIC IODINATIONS AND THE EVOLUTION OF $\mathrm{C}^{14} \mathrm{O}_{2}$ FROM GLUCOSE-1-C ${ }^{14}$ AND GLUCOSE$6-C^{14}$ IN A SHEFP THYROID HOMOGENATE. 


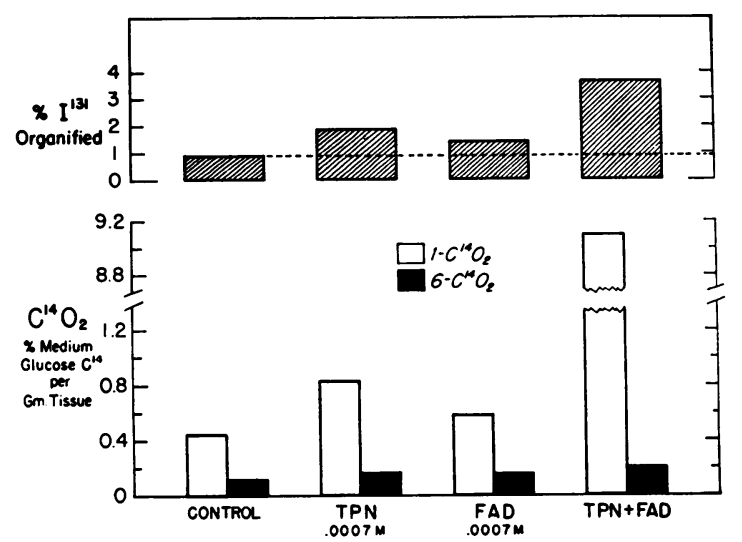

Fig. 13. The effects of TPN and FAD, alone and IN COMBINATION, ON ORGANIC IODINATIONS AND THE EVOLUTION OF $\mathrm{C}^{14} \mathrm{O}_{2}$ FROM GLUCOSE-1-C ${ }^{14}$ AND GLUCOSE-6-C $\mathrm{C}^{14}$ IN A SHEEP THYROID HOMOGENATE.

duction only slightly as compared with the usual effect of the tenfold greater concentration of TPN. The generation of $6-\mathrm{C}^{14} \mathrm{O}_{2}$ was also increased, but to a relatively slight extent. In one of these experiments, iodinations were also measured (Figure 12). These were slightly increased by DPN and markedly increased by the combination of coenzymes.

Flavin coenzymes. FAD increased the yield of 1-C ${ }^{14} \mathrm{O}_{2}$, but to a lesser extent than did TPN (Figure 13). The addition of FAD with TPN produced a greater stimulation of both $\mathrm{C}^{14} \mathrm{O}_{2}$ production and iodinations than could be accounted for
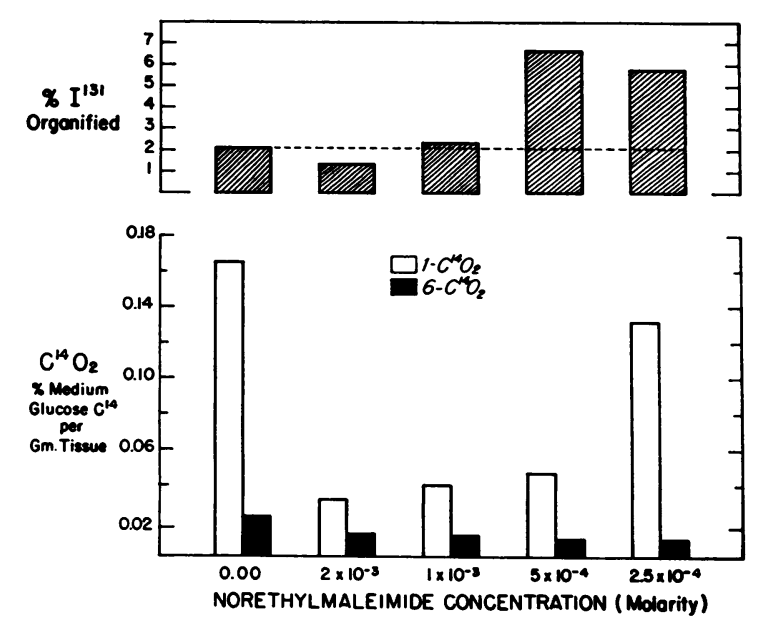

Fig. 14. The EFFects OF NORETHylmaleimide ON ORGANIC IODINATIONS AND THE EVOLUTION OF $\mathrm{C}^{14} \mathrm{O}_{2}$ FROM GLUCOSE-1-C $C^{14}$ AND GLUCOSE-6-C ${ }^{14}$ IN A HOMOGENATE OF SHEEP THYROID GLANDS.
TABLE $\mathrm{X}$

The effect of thyrotropin (TSH) on the production of carbon dioxide from differentially labeled glucose by slices of sheep thyroid gland

\begin{tabular}{|c|c|c|c|c|}
\hline \multirow{3}{*}{$\begin{array}{c}\text { Expt. } \\
\text { no. }\end{array}$} & \multicolumn{4}{|c|}{$\begin{array}{l}\mathrm{C}^{14} \mathrm{O}_{2} \text { production (\% added } \\
\text { glucose } / \mathrm{g} \text { tissue) }\end{array}$} \\
\hline & \multicolumn{2}{|c|}{ Control } & \multicolumn{2}{|c|}{$\mathrm{TSH}$} \\
\hline & $1-\mathrm{C}^{14}$ & $6-C^{14}$ & $1-\mathrm{C}^{14}$ & $6-\mathrm{C}^{14}$ \\
\hline 83 & 7.6 & 2.3 & 15.2 & 3.3 \\
\hline $86 a^{*}$ & 1.7 & 0.1 & 3.5 & 0.3 \\
\hline & 2.2 & 1.0 & 8.1 & 1.0 \\
\hline $93^{\circ}$ & 3.9 & 3.3 & 4.7 & 2.7 \\
\hline 94 & 1.3 & 0.4 & 3.1 & 0.4 \\
\hline 95 & 2.1 & 0.2 & 3.5 & 1.0 \\
\hline 96 & 3.5 & 1.3 & 5.8 & 1.0 \\
\hline 111 & 3.3 & 0.6 & 9.2 & 1.0 \\
\hline
\end{tabular}

* Slices from same gland: a, incubated for 45 minutes; $\mathrm{b}$, for 140 minutes.

by their individual effects. Other experiments confirmed the ability of FAD to enhance the stimulatory effect of TPN and revealed a similar action of FMN.

Methylene blue. In two experiments, the addition of $\mathrm{MB}$ to thyroid slices increased $1-\mathrm{C}^{14} \mathrm{O}_{2}$ from an average of 1.68 to 15.46 per cent and 6- $\mathrm{C}^{14} \mathrm{O}_{2}$ from 0.27 to 1.00 per cent of added glucose- $\mathrm{C}^{14}$ per $\mathrm{g}$ of tissue.

Sulfhydryl inhibitors. NEM, $2 \times 10^{-3} \mathrm{M}$, markedly inhibited the production of both 1 - and 6-C ${ }^{14} \mathrm{O}_{2}$; at this concentration iodinations were also inhibited. With decreasing concentrations of NEM, the production of $1-\mathrm{C}^{14} \mathrm{O}_{2}$ returned toward normal. In the case of $6-\mathrm{C}^{14} \mathrm{O}_{2}$ a doseresponse relationship was not apparent. As the evolution of $1-\mathrm{C}^{14} \mathrm{O}_{2}$ approached normal values, a stimulation of iodinations became evident (Figure 14). Like $\mathrm{NEM}, \mathrm{CuCl}_{2}$ and $\mathrm{HgCl}_{2}$ increased iodinations at concentrations which depressed the production of $\mathrm{C}^{14} \mathrm{O}_{2}$ (Table IX).

TSH (Table $X)$. In seven experiments in which thyroid slices were incubated with $\mathrm{TSH}$, yields of 1 - and $6-\mathrm{C}^{14} \mathrm{O}_{2}$ were increased by an average of 107 and 14 per cent, respectively. In three experiments in which these were measured, oxygen consumption and utilization of stable glucose were increased in TSH-supplemented flasks by an average of 15 and 102 per cent, respectively.

DISCUSSION

The present findings strongly suggest that the organification of iodide is linked to pathways of 
carbohydrate metabolism in the thyroid gland. Ideally, this relationship would have been characterized in the intact animal. However, the diffculty of altering the metabolic environment of a single organ in vivo precluded this approach. Even the surviving slice system was considered unfavorable for these studies since, in slices, controlled changes in the intracellular concentration of metabolites could not be produced. Furthermore, since intact thyroid slices are capable of concentrating inorganic iodide, changes in organically-bound iodine resulting from alterations in the iodide-concentrating mechanism could not be differentiated from those due to changes in the rate of organic binding of intrathyroidal iodide. These difficulties were overcome by the use of a homogenate system. This abolished the iodide-concentrating mechanism and also permitted the direct introduction of the compounds under study. The whole homogenate, rather than specific subcellular fractions, was chosen for study in order to preserve, as far as possible, the metabolic interrelationships present in the intact cell, and since the primary objective of this study was an elucidation of the metabolic relationships of the iodinating system, it was considered of great importance to preserve glycolytic activity in the preparation. Because of its reported effectiveness in maintaining glycolysis in liver homogenates (5), a potassium-rich medium was employed. This medium was found to support both glucose metabolism and iodination in the thyroid homogenate.

Several differences between the metabolism of iodine in the thyroid homogenate and the whole gland, however, raise the question of whether the homogenate is a suitable medium in which to study physiological iodinations. First, as the present and previous studies have shown (12), iodinations in the homogenate do not proceed appreciably beyond the synthesis of MIT; even when the quantity of iodine organified was increased by stimulatory factors or by the addition of inorganic iodide, appreciable quantities of diiodotyrosine were not formed. Second, the protein in which MIT is formed is not thyroglobulin (13). Finally, both Unknown 2 of Taurog and co-workers and the iodinated front-running material are prominent products of iodination in the homogenate, but are not found in significant proportions in the intact gland (14). The presence of these unusual iodinated products in the homogenate may indicate the accumulation of iodinated intermediates which, in the intact gland, are too rapidly utilized to be evident. However, if the front material is indeed an iodinated lipid, it would be an unlikely precursor of thyroid hormone but, like MIT, would result from an oxidation of iodide. That the same basic process determined the rate of formation of both MIT and front material is also suggested by the findings that rates of formation of origin and front materials underwent qualitatively similar changes under the influence of stimulatory or inhibitory agents. ${ }^{6}$ Thus, the evidence suggests that, within the homogenate, iodide is oxidized to a more reactive state which, in the face of structural disorganization, randomly iodinates available substrate.

In its inability to carry its iodinations beyond MIT, the thyroid homogenate resembles certain stages in the development of the fetal thyroid (15), certain neoplasms of the gland (16), and glands which have been frozen or stored (17). These, too, may show evidence of a preponderant or exclusive synthesis of MIT. Thus, the initial oxidation of iodide is probably a sturdy function resistant to cellular disruption or damage, and the homogenate system appears well suited to the study of this step in the intrathyroidal metabolism of iodine.

A pronounced variation was noted in the percentile iodinations achieved in unsupplemented samples of different homogenates. The reasons for this variability are not known, although several factors may have been contributory. Some variation in the elapsed time between the death of the animals and initiation of the experiments inevitably occurred. Pronounced differences in the size and vascularity of thyroid glands employed from day to day were not infrequent. These differences in gross appearance may have been re-

\footnotetext{
${ }^{6}$ In order to verify increases in iodinations, revealed by TCA-precipitation, chromatographic analysis of homogenates was performed at least once in the case of every stimulatory factor. Except for $\mathrm{HgCl}_{2}$, all stimulatory factors produced proportionate increases in front and origin materials. Mercury produced a greater increase in front than in origin material. Factors stimulatory to iodinations did not cause the appearance of significant quantities of iodinated products not found in control homogenates.
} 
flected in variations in the metabolic activity, in the rate of endogenous hormonal synthesis or in the concentration of inorganic iodide in such glands and in the homogenates to which they contributed. Therefore, in order to facilitate comparison of results obtained in replicate experiments, organic iodinations in the presence of modifying factors have been calculated not only as a fraction of added $\mathrm{I}^{131}$, but also as a percentage of organic iodinations obtained in control vessels.

Endogenous inhibition of iodinations. In early experiments, thyroid homogenates were dialyzed in order to determine whether dialyzable factors were essential for the organification of iodide. On the contrary, percentile iodinations were considerably and consistently increased by dialysis. Since percentile iodinations in both fresh and dialyzed homogenates were decreased by the addition of iodide, it seemed likely that the stimulatory effects of dialysis might have been due at least in part to a loss of iodide from the homogenate. However, an indication that the increase in iodinations observed in dialyzed homogenates was not due solely to loss of iodide was afforded by the observation that, like dialysis, storage of homogenates at $4^{\circ} \mathrm{C}$ increased subsequent percentile iodinations, although to a lesser extent. Since the concentration of inorganic iodide, if anything, increases during storage in the cold (18), the increases in percentile iodinations achieved in the stored homogenate must have reflected an increase in chemical iodinations. This suggested that the homogenate contained an inhibitor which was labile to storage and perhaps dialyzable.

These characteristics of the endogenous inhibitor suggested that it might be a nonprotein, sulfhydryl-containing compound, such as glutathione. This tripeptide is present in many tissues (19), including the thyroid (20). It is dialyzable, autooxidizes readily, especially in the presence of traces of copper, and has been shown to inhibit iodinations in the thyroid homogenate system (21). Furthermore, previous workers have reported that copper increases organic iodinations in the homogenate system $(21,22)$. Although this effect has been ascribed to the participation of copper either as a cofactor for a thyroidal iodinase (21) or, nonphysiologically, as a direct oxidant of iodide (22), the present observations were con- sistent with the hypothesis that copper increased organic iodinations by decreasing the concentration of an endogenous sulfhydryl inhibitor of iodinations. This could result from either formation of mercaptides or catalysis of sulfhydryl autooxidation (11). This conclusion was supported by the finding that the stimulatory effects of copper were shared by both mercury and the even more nearly specific sulfhydryl inhibitor, NEM. Furthermore, since dialysis of the homogenate altered the response to these agents, rendering stimulatory concentrations either less so or frankly inhibitory, it seemed unlikely that the heavy metals could be acting as direct oxidants of iodide or cofactors for an iodinating enzyme. These observations also indicated that dialysis of homogenate did more than merely lower the concentration of inorganic iodide. Rather, dialysis appeared to have removed the endogenous inhibitor of iodinations which the sulfhydryl reagents themselves were thought to attack. Within this context, the inhibitory effects of high concentrations of sulfhydryl reagents in the fresh homogenate, as well as the inhibition of iodinations produced in dialyzed homogenates by lower concentrations which had previously been stimulatory, could be explained by the sulfhydryl dependency of several glycolytic enzymes (23) which apparently participate in the iodination mechanism. With high concentrations of NEM, this supposition was confirmed by demonstrating a pronounced decrease in the evolution of $\mathrm{CO}_{2}$ from $\mathrm{C}^{14}$-labeled glucose.

If the endogenous inhibitor were indeed $\mathrm{GSH}$, then its effect on iodinations could be explained by certain well known reactions of this compound. Thus, GSH might act as a competitive substrate for an oxidant of iodide, such as $\mathrm{H}_{2} \mathrm{O}_{2}$ (11): $\mathrm{H}_{2} \mathrm{O}_{2}+2 \mathrm{GSH} \rightleftarrows \mathrm{GSSG}+2 \quad \mathrm{H}_{2} \mathrm{O}$. Alternatively, GSH might reduce an oxidized form of iodine, as in the following reaction: $2 \mathrm{GSH}+2 \mathrm{I}^{0}$ $\rightleftarrows \mathrm{GSSG}+2 \mathrm{H}^{+}+2 \mathrm{I}^{-}$. Indeed, the facility with which the latter reaction proceeds in vitro permits its use in the measurement of GSH and other reducing substances in blood and other tissues $(24){ }^{?}$

\footnotetext{
7 This technique depends on the re-reduction by GSH and other reducing substances of iodine generated from iodide by potassium iodate. It appeared to afford a means of assessing the potential of substances within a thyroid homogenate to reduce iodine and to behave like the pos-
} 
The greater inhibitory effect of GSH than of GSSG was consistent with the foregoing reactions, and indicated some limitation in the ability of the unsupplemented homogenate to reduce the oxidized form. This limitation was overcome by the addition of TPN. This converted the rather variable effect of GSSG to a consistent inhibition, an effect which was even more readily apparent when iodinations in the presence of TPN and GSSG were compared with those obtained with TPN alone. Enhancement by TPN of the GSSG-induced inhibition of iodinations can be ascribed to the rapid reduction of TPN within the homogenate, since TPNH is a coenzyme for glutathione reductase (25), an enzyme known to be present in the thyroid gland (26).

If GSH is indeed the endogenous inhibitor of iodinations, ${ }^{8}$ the oxygen dependency of iodination rates may be due in part to the propensity of GSH to undergo oxidation under conditions of increasing oxygen tension. However, this alone cannot explain the absolute oxygen requirement of the iodinating system, since anoxia inhibited iodinations in homogenates from which the endogenous inhibitor had been removed by dialysis or by the addition of sulfhydryl reagents.

The role of carbohydrate metabolism. To define the relation between carbohydrate metabolism and organic iodinations in the thyroid homogenate, several methods were employed to alter the activity of pathways of glucose catabolism. Extensive studies of the effects of adding substrates were not performed. However, succinate, and possibly isocitrate and oxaloacetate, appeared to stimulate iodinations. In view of the proposed mechanism of iodination, to be discussed below, the stimulation produced by succinate is of particular interest, since succinate, unlike other car-

tulated endogenous inhibitor of iodinations. Iodometric titrations revealed a virtually complete loss of reducing materials following dialysis of the homogenate or addition of stimulatory concentrations of $\mathrm{CuCl}_{2}$. Partial loss of reducing materials occurred upon storage of homogenates.

${ }^{8}$ The evidence which suggests that GSH is the endogenous inhibitor of iodinations would also be consistent with the possibility that the effect of GSH is mediated in part or entirely by compounds such as ascorbic acid with which glutathione is in oxidation-reduction equilibrium (27). In the present experiments, ascorbic acid proved to be markedly inhibitory to iodinations in the homogenate system. bohydrate intermediates, is directly oxidized by a flavin dehydrogenase (28). The lack of effect of other substrates is difficult to interpret; their endogenous concentration in the homogenate may not have imposed any rate-limitation. Sufficient experiments to determine the effects of adding substrates to dialyzed homogenates, in which endogenous substrates can be presumed to be depleted, were not performed.

It has been suggested that the hexose monophosphate (HMP) shunt and the Embden-Meyerhof glycolytic pathway can be selectively stimulated by the addition of pyridine nucleotide coenzymes specifically associated with the dehydrogenases of each pathway. Thus, it is thought that the addition of TPN increases the activity of the HMP shunt (29), while DPN stimulates glycolysis $(5,29)$. The ability of both TPN and DPN to increase iodinations in the homogenate system therefore implicated carbohydrate metabolism in the regulation of organic iodinations. However, the more consistent and greater stimulatory effect of TPN than of DPN suggested that the two coenzymes might stimulate iodinations by different mechanisms. It was interesting, therefore, to determine how the effectiveness of each coenzyme was related to its oxidation-reduction state. The effects of adding the oxidized and reduced forms could not be directly compared because of the rapidity with which coenzymes added to tissues are brought to oxidation-reduction equilibrium. By adding each coenzyme together with its specific reducing system (isocitrate-isocitrate dehydrogenase for TPN ; ethyl alcohol-alcohol dehydrogenase for DPN), it was possible to maintain within the homogenate higher concentrations of reduced coenzyme than would have followed the addition of the coenzyme alone. Under these conditions, the stimulatory effectiveness of TPN was enhanced, while DPN became inhibitory. These findings afforded further evidence of a difference in the action of the two coenzymes on organic iodinations, in that TPN stimulated iodinations in its reduced form, while DPN was apparently effective only in its oxidized form.

As shown in Figure 7, however, there appeared to be a limit beyond which increasing the concentration of TPNH no longer increased iodinations. In this experiment, the stimulation of iodinations which followed the addition of TPN 
continued at a time when the concentration of TPNH was no longer increasing. However, the further addition of TPN, with the attainment of a new equilibrium at an even higher concentration of TPNH, was attended by no further stimulation of iodination. In the presence of excess $\mathrm{TPNH}$, other factors apparently become ratelimiting for iodinations.

An explanation for the seemingly paradoxical inhibition of iodinations produced by the addition of lower concentrations of TPN was sought in the interaction between TPN and the endogenous inhibitor. Since exogenous GSSG was capable of changing the effect of added TPN from stimulation to inhibition, it seemed possible that the effect of TPN could be similarly modified by the endogenous inhibitor. Support for this hypothesis was obtained from the observation that either dialysis or addition of NEM not only changed the effect of the low concentration of TPN $\left(7 \times 10^{-5}\right.$ M) from inhibition to stimulation. but also increased the stimulatory effect of full concentrations of the coenzyme $\left(7 \times 10^{-4} \mathrm{M}\right)$. Thus, the relatively low concentration of endogenous inhibitor (presumably glutathione) induced inhibition in conjunction with low concentrations of added TPN, just as the high concentrations of added GSSG produced inhibition with full concentrations of added TPN.

Thus, the stimulation of organic iodinations produced by TPN is limited by the presence of an endogenous inhibitor which may be glutathione. This contrasts with the mechanism of action of the heavy metals and of NEM; their stimulatory effect is evident only in the presence of an endogenous inhibitor whose action they prevent. TPN is rapidly reduced in the homogenate, and the resulting TPNH has two opposing effects on iodination: a stimulatory action discussed in greater detail below, and an inhibitory action which is related to the reduction of endogenous GSSG. Increased organic iodinations ensue if, as when large concentrations of TPN are added, the stimulatory effect of TPNH outstrips the balancing inhibitory action. Under physiological circumstances, such an internally damped system might have considerable value in stabilizing the rate of organic iodinations during changes in metabolic activity within the thyroid gland.

Experiments with 1-C ${ }^{14}$ - and 6- ${ }^{14}$-labeled glu- cose were performed in order to gain further insight into the relation between carbohydrate metabolism and organic iodinations, to determine the pathways in the thyroid responsible for the reduction of TPN, and to elucidate the mechanism of action of other factors stimulatory to iodinations. The complexities of employing differentially labeled glucose to estimate the relative proportion or absolute amounts of glucose metabolized via the Embden-Meyerhof pathway vis a vis the HMP shunt have recently been reviewed (30). It is apparent that measurements of $\mathrm{C}^{14} \mathrm{O}_{2}$ production from glucose-1- $\mathrm{C}^{14}$ and glucose- $6-\mathrm{C}^{14}$ do not alone make such estimates possible. Nevertheless, a preponderant evolution of $\mathrm{C}^{14} \mathrm{O}_{2}$ from glucose-1$\mathrm{C}^{14}$ over that from glucose-6-C $\mathrm{C}^{14}$ provides evidence for the operation of the shunt. Furthermore, provided that proportionate re-formation of glucose from products of shunt activity remains unaltered, an increase in the evolution of $\mathrm{C}^{14} \mathrm{O}_{2}$, preponderantly from glucose-1- $\mathrm{C}^{14}$, will indicate an increase in the activity of the HMP shunt and consequently in the rate of generation of TPNH. The present findings with labeled glucose have been employed and interpreted in that light.

The greater evolution of $\mathrm{C}^{14} \mathrm{O}_{2}$ from glucose$1-\mathrm{C}^{14}$ than from glucose- $6-\mathrm{C}^{14}$ found during the present studies in both slices and homogenates of thyroid tissue indicated that the HMP shunt is operative in the thyroid gland. ${ }^{9}$ The data further suggested that an acceleration of the HMP shunt, induced by the addition of TPN, was responsible for the reduction of at least a considerable proportion of the added coenzyme and that in the thyroid, as in other tissues, the availability of TPN is an important rate-limiting factor for this metabolic pathway.

The stimulatory effect of DPN on organic iodinations was more variable and less pronounced than that of TPN, suggesting that its action in the homogenate was more complex. Experiments in which iodine or glucose metabolism or both were measured indicated that this was indeed the

\footnotetext{
9 Field and his co-workers have also presented evidence for the operation of the HMP shunt in thyroid slices (31). These workers were unable to demonstrate generation of $\mathrm{C}^{14}()_{2}$, from labeled glucose in thyroid homogenates. This discrepancy with the present findings may have resulted from the difference in homogenization medium employed in the two studies.
} 
case, and that the effect of DPN depended upon the concentration of TPN in the homogenate. Thus, in the presence of concentrations of exogenous TPN which inhibited iodinations when added alone, inhibitory or insignificant effects of DPN on organic iodinations were changed to stimulation and stimulatory effects were increased.

This synergism between the two pyridine nucleotides might possibly have been due to the action of a transhydrogenase (32), oxidizing DPNH and reducing TPN to its stimulatory form, TPNH. However, the stimulatory effect of DPN on iodinations was decreased or abolished by the concomitant addition of a DPN-reducing system. The converse would have been expected had a DPNH to TPN transhydrogenation been responsible for the stimulatory effect of DPN. Nevertheless, attempts were made to demonstrate such a transhydrogenase in thyroid homogenates. By a method analogous to that employed by Colowick, Kaplan, Neufeld and Ciotti (33), the reduction of TPN was assessed spectrophotometrically following addition of a low catalytic concentration of DPN and a DPN-reducing system (ethyl alcohol-alcohol dehydrogenase). No transfer of hydrogen from DPNH to TPN could be demonstrated by this method.

Since DPN also appeared to synergize the action of TPN on the HMP shunt, other interactions between the two pyridine nucleotides seemed possible. First, in the presence of an active TPNH to DPN transhydrogenase (33), added DPN might increase the activity of the HMP shunt by speeding regeneration of the hydrogen acceptor, TPN. However, if such a transhydrogenase were present, addition of DPN should tend to reduce the availability of $\mathrm{TPNH}$ and thereby decrease organic iodinations; the converse was actually the case. Furthermore, direct spectrophotometric assay by a technique analogous to that described above failed to reveal a TPNH to DPN transhydrogenase in thyroid homogenates.

A further possible mechanism for the effect of DPN involves the generation of TPN from DPN via a DPN-kinase (34). Partial conversion of DPN to TPN might explain the greater stimulation of iodinations achieved by TPN than DPN when added to homogenates in equal concentrations. The ability of DPN to reverse the inhibition of iodinations produced by $7 \times 10^{-5} \mathrm{M}$ TPN would also be consistent with this hypothesis. This explanation, however, is not consistent with the observation that in the presence of $7 \times 10^{-4} \mathrm{M}$ DPN, TPN in a concentration of $7 \times 10^{-5} \mathrm{M}$ produced a far greater stimulation of $1-\mathrm{C}^{14} \mathrm{O}_{2}$ production than did $7 \times 10^{-4} \mathrm{M}$ TPN alone.

For these reasons, an alternative explanation, similar to that proposed by others to account for the synergistic action of TPN and DPN on hepatic synthesis of fatty acids (35) seemed more attractive. This hypothesis suggests that DPN increases the activity of the HMP shunt by accelerating the metabolism of 3-carbon products of the shunt which re-enter the Embden-Meyerhof pathway. Addition of DPN would thereby increase the generation of TPNH. In the presence of low endogenous concentrations of TPN, DPN might increase the generation of TPNH to the same extent as the addition of low $(7 \times$ $10^{-5} \mathrm{M}$ ) concentrations of TPN alone. Inhibition of iodinations would then result from an accelerated reduction of GSSG. If the endogenous concentration of TPN were higher or were increased by exogenous TPN, addition of DPN might facilitate the generation of sufficient TPNH so that its stimulatory effect on iodinations would become manifest. Thus, the influence of DPN on organic iodinations would be mediated through its effects on the generation of TPNH.

It seemed unlikely, however, that reduced TPN per se could be responsible for the oxidation of iodide which is requisite for organification. Rather, TPNH must serve as an intermediate in the generation of an agent capable of oxidizing iodide. The sensitivity of the iodinating system to inhibition by cyanide and its absolute oxygen dependency focused attention on the possibility that further hydrogen transfers along the cytochrome system might be required for the formation of the postulated oxidant. However, in the present experiments, in contrast to the results of other studies (36), addition of cytochrome $C$ to the whole homogenate had little effect on organic iodinations. Antimycin A, which inhibits reduction of the cytochromes (37), also failed to inhibit iodinations (38), and in the present experiments was slightly stimulatory. This favored the hypothesis that the cytochromes did not function as part of the iodinating system. Methylene blue (MB) permits the direct transfer of electrons to oxygen, thereby 
bypassing the cytochrome system. MB was therefore added to homogenates to compete with the cytochrome system as a hydrogen acceptor. The marked increase in the evolution of $1-\mathrm{C}^{14} \mathrm{O}_{2}$ which followed the addition of $\mathrm{MB}$ indicated its ability to oxidize TPNH in the intact thyroid slice, as it has been thought to do in liver slices (39). Furthermore, the stimulatory effect of MB on iodinations in the homogenate and its synergism with added TPN in this regard not only seemed to rule out a necessary participation of the cytochromes in the iodinating system, but also suggested that hydrogen transfers from TPNH to MB might constitute a partial model of the physiological iodinating system.

Unlike TPNH, reduced $\mathrm{MB}$ is capable of undergoing auto-oxidation to yield $\mathrm{H}_{2} \mathrm{O}_{2}$ (40). For some years, it has been thought that thyroidal iodide is oxidized by $\mathrm{H}_{2} \mathrm{O}_{2}$ in a reaction catalyzed by a glandular peroxidase $(41,42)$. Although $\mathrm{H}_{2} \mathrm{O}_{2}$ has not itself been demonstrated in the thyroid, a halogen-peroxidase, apparently specific for iodide has recently been found (43) and a number of peroxidase inhibitors are known to be potent antithyroid agents (44). Furthermore, catalase has been shown to inhibit iodinations in both a soluble tyrosine-iodinating system derived from submaxillary gland (45) and in a thyroid mitochondrial-microsomal preparation (13). In the present experiments, catalase was moderately inhibitory of organic iodinations in whole thyroid homogenates. Finally, hydrogen peroxide has been shown to overcome the inhibitory effect of anoxia on iodinations in the tyrosine-iodinating system (45). It therefore seemed possible that the stimulation of iodinations induced by $\mathrm{MB}$ in the present experiments was due to its ability to generate $\mathrm{H}_{2} \mathrm{O}_{2}$ after reduction by TPNH.

In physiological systems, FAD-linked metalloproteins are the only known sources of $\mathrm{H}_{2} \mathrm{O}_{2}$. These aerobic dehydrogenases are inhibited by cyanide and are capable of being oxidized by MB. These properties suggested that, in the physiological iodinating system, a flavin enzyme might serve to accept hydrogen from TPNH and then produce $\mathrm{H}_{2} \mathrm{O}_{2}$ by auto-oxidation. For these reasons, the effects of added flavins in the thyroid homogenate were assessed. Although FAD alone induced only slight stimulation of organic iodinations and the evolution of $\mathrm{C}^{14} \mathrm{O}_{2}$ from labeled glu- cose, it acted synergistically with added TPN to produce a marked increase in iodinations and a profound increase in $\mathrm{C}^{14} \mathrm{O}_{2}$. Within the context of the $\mathrm{H}_{2} \mathrm{O}_{2}$ hypothesis, it appeared that FAD potentiated the action of TPN on the HMP shunt by maintaining the TPN in the oxidized state, while the resulting reduced FAD underwent autooxidation to form the oxidant of iodide, $\mathrm{H}_{2} \mathrm{O}_{2}$.

It was uncertain, however, that the effects of added FAD were indeed related to the function of the physiological iodinating system. Although previous workers had shown that iodinations in a thyroid mitochondrial-microsomal preparation could be increased by addition of flavins (38), this stimulatory effect was not abolished by anoxia. No explanation is apparent for the discrepancy between these and the present findings, in which FAD failed to stimulate iodinations in the absence of oxygen. More important, however, was the observation that in a tissue-free system, flavins could catalyze a light-dependent oxidation of iodide $(46,47)$ which could result in the iodination of added serum proteins. For these reasons, the effects of light and dark on organic iodinations in the present homogenate system, and on the actions of TPN and flavins therein, were assessed. The findings of earlier workers were confirmed, in that iodination of human serum albumin in a simple buffer medium could be effected by FAD in a reaction inhibited by exclusion of oxygen and light. However, TPN had no effect on the flavin-stimulated iodinations in this tissue-free system. In the thyroid homogenate, in contrast, exclusion of light had no effect on control iodinations, partially inhibited the increase in iodinations produced by FAD alone, but had no effect on the pronounced increase in iodinations which followed the addition of FAD with TPN. It seemed, therefore, that the added FAD was indeed participating in the physiological iodinating system of the homogenate, and that the energy for the flavin-stimulated oxidation of iodide, which was derived from incident light in the tissue-free system, was, in the thyroid homogenate, supplied by an endogenous metabolic source.

Most of these studies were performed with FAD. However, FMN was similarly effective. This lack of specificity with regard to coenzyme and the fact that the flavin-supplemented system seemed inefficient in the utilization of metabolic 
energy, causing a proportionately much greater stimulation of $1-\mathrm{C}^{14} \mathrm{O}_{2}$ production than of iodinations, makes it unlikely that free flavins are ratecontrolling intermediates in the physiological iodinating system. Rather, it seems likely that in the thyroid, as elsewhere, the flavins are tightly bound to the enzymes with which they function.

Pronounced differences in the behavior of thyroid particulate preparations of differing nature have been noted. Thus, Tong and Chaikoff have reported that cytochrome $\mathrm{C}$ stimulated iodinations in the whole homogenate, but not in a mitochondrial-microsomal preparation (36), while the converse was true of FMN. Earlier, the stimulatory effect of flavins in a mitochondrial-microsomal preparation was reported to persist despite anoxia (38); in the present experiments a moderate stimulatory effect of flavins was obtained in whole homogenates and was distinctly inhibited by anoxia. Similarly, the present evidence that TPNH-linked dehydrogenations of the HMP shunt are regulatory to iodinations in the whole homogenate would presumably not apply to the mitochondrial-microsomal preparations. Here, however, mechanisms for the generation of reduced pyridine nucleotides and flavoproteins via the Krebs cycle could also lead to the formation of $\mathrm{H}_{2} \mathrm{O}_{2}$.

Because of these differences in the behavior of various broken cell preparations, experiments were undertaken to ascertain whether an increase in TPN-linked dehydrogenations could be demonstrated as a characteristic of physiological stimulation of the intact thyroid cell. For this purpose, TSH was employed to stimulate organic iodinations in thyroid slices. Relative effects on the evolution of $\mathrm{C}^{14} \mathrm{O}_{2}$ from 1-C $\mathrm{C}^{14}$ - and 6-C $\mathrm{C}^{14}$-labeled glucose were again determined as an index of changes in the rate of generation of $\mathrm{TPNH}$. While these studies were in progress, Field, Pastan, Johnson and Herring (31) reported the results of similar observations. The present results are entirely in accord with the findings of these workers, who observed that TSH increases the production of $\mathrm{C}^{14} \mathrm{O}_{2}$, preponderantly from 1- $\mathrm{C}^{14}$ - as compared with 6- $\mathrm{C}^{14}$-labeled glucose, and who, like Freinkel (48), reported an increase in total glucose utilization under these conditions. These results indicate that $\mathrm{TSH}$, a physiological stimulator of iodinations, is, in the intact thyroid cell, capable of enhancing those metabolic processes which, in the thyroid homogenate, provide energy for the oxidation of iodide. For reasons already noted, however, the findings do not permit conclusions as to whether TSH specifically or preponderantly stimulates the HMP shunt as compared to the Embden-Meyerhof pathway. Furthermore, they afford no evidence of how the evident increase in the turnover of TPNH is effected. Thus, TSH might accelerate the reduction of TPN by stimulating the HMP shunt, either specifically or as part of a general increase in glucose catabolism. Alternatively, TSH might stimulate hydrogen transfers within the physiological iodinating mechanism at some point distal to $\mathrm{TPNH}$. The resulting increase in the generation of TPN from TPNH would increase the activity of the HMP shunt secondarily. The latter mode of action, analogous in some respects to that proposed for FAD, would seem more favorable to a stimulation of iodinations, since it would tend to decrease, rather than increase, the availability of TPNH for the reduction of GSSG. Finally, TSH might increase the availability of TPN by activating a DPN-kinase, if such is present in thyroid tissue (34). This explanation would be consistent with the observation that in the guinea pig thyroid, which is relatively inactive, the concentration of triphosphopyridine nucleotides ( TPN $+\mathrm{TPNH})$ is very low and is far exceeded by the concentration of diphosphopyridine nucleotides (DPN + DPNH) (49).

On the basis of the present findings, it is proposed that the energy for the thyroid organification of iodide is derived from glucose metabolism via TPN-linked dehydrogenations. TPNH is oxidized by a flavin enzyme which in turn reduces oxygen to form $\mathrm{H}_{2} \mathrm{O}_{2}$. The latter oxidizes iodide in a reaction catalyzed by a thyroidal peroxidase. DPN has a permissive action on the operation of the HMP shunt, but probably does not directly contribute hydrogen to the iodinating system. Dehydrogenations which reduce TPN are also capable of inhibiting iodinations by accelerating the reduction of GSSG. The latter reaction would serve as a "governor" on the acceleration of iodinations which would otherwise follow an increase in glucose catabolism.

Earlier observations have indicated that the maintenance of adequate intrathyroidal stores of 
iodide for hormonal biogenesis depends upon phosphate bond energy derived from glucose catabolism $(3,4)$. The present observations afford evidence of a relation between glucose catabolism and the next step in hormonal biogenesis, the oxidation of iodide. The role of TPN-linked dehydrogenations in the latter reactions is of particular interest in view of recent indications that the synthesis of protein $(50)$ and fat $(35,51)$ may be TPNH-dependent. Thus, the energy for increased hormonal biogenesis (accelerated synthesis of thyroglobin plus increased iodinations) and for its usual concomitant, glandular hyperplasia, may be derived via the same metabolic pathways. In this way, certain functional and structural effects of TSH on the thyroid gland could be mediated by an action upon a single metabolic site.

\section{SUMMARY}

The role of intermediary carbohydrate metabolism in regulating the rate of organic iodinations in thyroid homogenates has been investigated. Evidence was obtained for the presence of an endogenous inhibitor of iodinations whose activity was diminished or lost following storage, dialysis, or addition of sulfhydryl inhibitors.

Rates of organic iodination were regulated by TPN-linked dehydrogenations. Reduced TPN participated in both inhibitory and stimulatory interactions with the physiological iodinating system. The former appeared to result from an enhanced generation of the endogenous inhibitor, presumably reduced glutathione. The stimulatory interaction was synergized by flavin cofactors and methylene blue in reactions thought ultimately to yield hydrogen peroxide, an oxidant of iodide.

Dehydrogenations in the hexose monophosphate shunt appeared to be the principal source of reduced TPN. DPN and flavin cofactors acted synergistically with TPN in stimulating shunt activity and increasing generation of TPNH. In the intact thyroid cell, activity of the shunt was enhanced by TSH, a physiological stimulator of iodinations.

On the basis of these observations, an internally damped sequence of hydrogen transfers via TPN and a flavin enzyme is proposed as a means of utilizing energy from glucose metabolism in the oxidation of iodide.

\section{REFERENCES}

1. Berson, S. A. Pathways of iodine metabolism. Amer. J. Med. 1956, 20, 653.

2. Ingbar, S. H., and Freinkel, N. Thyroid hormones in Hormones in Human Plasma, H. N. Antoniades, Ed. Boston, Little, Brown, 1960, pp. 515-579.

3. Freinkel, N., and Ingbar, S. H. Effect of metabolic inhibitors upon iodide transport in sheep thyroid slices. J. clin. Endocr. 1955, 15, 598.

4. Slingerland, D. W. The influence of various factors on the uptake of iodine by the thyroid. J. clin. Endocr. 1955, 15, 131.

5. Wenner, C. E., Dunn, D. F., and Weinhouse, S. A study of glucose oxidation in whole tissue homogenates. J. biol. Chem. 1953, 205, 409.

6. Ahn, C. S., and Rosenberg, I. N. Non-iodide radioactivity in commercial solutions of sodium radioiodide $\left(\mathrm{I}^{131}\right)$. Endocrinology 1961, 68, 50.

7. Litonjua, A. D., and Freinkel, N. Personal communication.

8. Taurog, A., Tong, W., and Chaikoff, I. L. An unidentified iodine compound formed by incubation of cell-free preparations of tissue with iodide- $\mathrm{I}^{131}$. J. biol. Chem. 1957, 227, 759.

9. Glock, G. E., and McLean, P. Further studies on the properties and assay of glucose-6-phosphate dehydrogenase and 6-phosphogluconate dehydrogenase of rat liver. Biochem. J. 1953, 55, 400.

10. Huggett, A. St. G., and Nixon, D. A. Use of glucose oxidase, peroxidase, and $o$-dianisidane in determination of blood and urinary glucose. Lancet 1957, 2, 368.

11. Wieland, T. Chemistry and properties of glutathione in Glutathione, S. Colowick, A. Lazarow, E. Racker, D. R. Schwarz, E. Stadtman and H. Waelsch, Eds. New York, Academic Press, 1954, pp. $45-59$.

12. Taurog, A., Potter, G. D., and Chaikoff, I. L. Conversion of inorganic $\mathrm{I}^{131}$ to organic $\mathrm{I}^{131}$ by cell-free preparations of thyroid tissue. J. biol. Chem. 1955, 213, 119.

13. deGroot, L. J., and Carvalho, E. Iodide binding in thyroid cellular fractions. J. biol. Chem. 1960, 235, 1390.

14. deGroot, L. J., and Berger, J. E. A note on inorganic oxidation products of $\mathrm{I}^{131}$ formed in biological systems. Endocrinology 1960, 67, 657.

15. Trunnell, J. B., and Wade, P. Factors governing the development of the chick embryo thyroid. II. Chronology of the synthesis of iodinated compounds studied by chromatographic analysis. J. clin. Endocr. 1955, 15, 107.

16. Tata, J. R., Rall, J. E., and Rawson, R. W. Studies of an iodinated protein in the serum of subjects with cancer of the thyroid. J. clin. Endocr. 1956, 16, 1554.

17. Mayer, S. W., Kelly, F. H., and Morton, M. E. Formation of radioactive protein-bound monoio- 
dotyrosine by stored thyroid slices. Science 1956 , 123, 26.

18. Dowling, J. T., Freinkel, N., and Ingbar, S. H. Unpublished observations.

19. Jocelyn, P. C. Glutathione metabolism in animals in Glutathione, Biochemical Society Symposia, no. 17, E. M. Crook, Ed. London, Cambridge University Press, 1959, p. 43.

20. Ingbar, $\mathrm{S}$. $\mathrm{H}$. Unpublished observations.

21. Weiss, B. Utilization of radioactive iodide by cellfree preparations of beef thyroid tissue. J. biol. Chem. 1953, 201, 31.

22. Fawcett, D. M., and Kirkwood, S. Tyrosine iodinase. J. biol. Chem. 1954, 209, 249.

23. Barron, E. S. G. Thiol groups of biological importance. Advanc. Enzymol. 1951, 11, 201.

24. Woodward, G. E., and Fry, E. G. The determination of blood glutathione. J. biol. Chem. 1932, 97, 465.

25. Rall, T. W., and Lehninger, A. L. Glutathione reductase of animal tissues. J. biol. Chem. 1952, 194, 119.

26. Manso, C., and Wrobléwski, F. Glutathione reductase activity in blood and body fluids. J. clin. Invest. 1958, 37, 214.

27. Hopkins, F. G., and Morgan, E. J. Some relations between ascorbic acid and glutathione. Biochem. J. 1936, 30, 1446.

28. Green, D. E., and Fleischer, S. The mitochondrial system of enzymes in Metabolic Pathways, D. M. Greenberg, Ed. New York, Academic Press, 1960, pp. 41-96.

29. Wenner, C. E., and Weinhouse, S. An isotope tracer study of glucose catabolism pathways in liver. J. biol. Chem. 1956, 219, 691.

30. Katz, J., and Wood, H. G. The use of glucose- $\mathrm{C}^{14}$ for the evaluation of the pathways of glucose metabolism. J. biol. Chem. 1960, 235, 2165.

31. Field, J. B., Pastan, I., Johnson, P., and Herring, B. Stimulation in vitro of pathways of glucose oxidation in thyroid by thyroid-stimulating hormone. J. biol. Chem. 1960, 235, 1863.

32. Talalay, P., and Williams-Ashman, H. G. Participation of steroid hormones in the enzymatic transfer of hydrogen. Recent Progr. Hormone Res. $1960,16,1$.

33. Colowick, S. P., Kaplan, N. O., Neufeld, E. F., and Ciotti, M. M. Pyridine nucleotide transhydrogenase. I. Indirect evidence for the reaction and purification of the enzyme. J. biol. Chem. 1952, 195, 95.

34. Wang, T. P., and Kaplan, N. O. Kinases for the synthesis of coenzyme $\mathrm{A}$ and triphosphopyridine nucleotide. J. biol. Chem. 1954, 206, 311.

35. Siperstein, M. D., and Fagan, V. M. Studies on the relationship between glucose oxidation and intermediary metabolism. I. The influence of glycolysis on the synthesis of cholesterol and fatty acid in normal liver. J. clin. Invest. 1958, 37, 1185.

36. Tong, W., and Chaikoff, I. L. Stimulating effects of cytochrome $\mathrm{C}$ and quinones on ${ }^{181} \mathrm{I}$ utilization by cell-free sheep thyroid gland preparations. Biochim. biophys. Acta 1961, 46, 259.

37. Potter, V. R., and Reif, A. E. Inhibition of an electron transport component by antimycin A. J. biol. Chem. 1952, 194, 287.

38. Tong, W., Taurog, A., and Chaikoff, I. L. Activation of the iodinating system in sheep thyroid particulate fractions by flavin cofactors. J. biol. Chem. 1957, 227, 773.

39. Cahill, G. F., Jr., Hastings, A. B., Ashmore, J., and Zottu, S. Studies on carbohydrate metabolism in rat liver slices. $\mathrm{X}$. Factors in the regulation of pathways of glucose metabolism. J. biol. Chem. 1958, 230, 125.

40. Baldwin, E. Dynamic Aspects of Biochemistry, 3rd ed. Cambridge, Cambridge University Press, 1957.

41. De Robertis, E., and Grasso, R. Peroxide activity of the thyroid gland under normal and experimental conditions. Endocrinology 1946, 38, 137.

42. Astwood, E. B. Mechanisms of action of various antithyroid compounds. Ann. N. Y. Acad. Sci. 1949, 50, 419.

43. Alexander, N. M. Iodide peroxidase in rat thyroid and salivary glands and its inhibition by antithyroid compounds. J. biol. Chem. 1959, 234, 1530.

44. Rosenberg, I. N. The antithyroid activity of some compounds that inhibit peroxidase. Science 1952, 116, 503.

45. Serif, G. S., and Kirkwood, S. Enzyme systems concerned with the synthesis of monoiodotyrosine. II. Further properties of the soluble and mitochondrial systems. J. biol. Chem. 1958, 233, 109.

46. Soodak, M., and Maloof, F. Iodination by a cytoplasmic particulate preparation of hog thyroid. Fed. Proc. 1959, 18, 328.

47. Soodak, M., and Maloof, F. The photoinduced iodination of some proteins. Fed. Proc. 1960, 19, 173.

48. Freinkel, N. Further observations concerning the action of pituitary thyrotropin on the intermediate metabolism of sheep thyroid tissue in vivo. Endocrinology 1960, 66, 851.

49. Glock, G. E., and McLean, P. Levels of oxidized and reduced diphosphopyridine nucleotide and triphosphopyridine nucleotide in animal tissues. Biochem. J. 1955, 61, 388.

50. Wilson, J. D., and Siperstein, M. D. Studies on the relationship between glucose oxidation and intermediary metabolism. III. The influence of pyridine nucleotides on protein synthesis. J. clin. Invest. $1959,38,317$.

51. Langdon, R. G. The biosynthesis of fatty acids in rat liver. J. biol. Chem. 1957, 226, 615. 